\title{
Towards precision medicine for pain: diagnostic biomarkers and repurposed drugs
}

\author{
A. B. Niculescu, ${ }^{1,2,3} \cdot$ H. Le-Niculescu ${ }^{1} \cdot$ D. F. Levey ${ }^{1} \cdot$ K. Roseberry ${ }^{1} \cdot$ K. C. Soe ${ }^{1} \cdot$ J. Rogers ${ }^{1} \cdot$ F. Khan ${ }^{1} \cdot$ T. Jones ${ }^{3} \cdot$ \\ S. Judd ${ }^{1} \cdot$ M. A. McCormick ${ }^{1} \cdot$ A. R. Wessel ${ }^{1} \cdot$ A. Williams ${ }^{3} \cdot$ S. M. Kurian ${ }^{4} \cdot$ F. A. White $\mathbb{1}^{2,3,5}$
}

Received: 5 June 2018 / Revised: 30 October 2018 / Accepted: 10 December 2018 / Published online: 12 February 2019

(c) The Author(s) 2019. This article is published with open access

\begin{abstract}
We endeavored to identify objective blood biomarkers for pain, a subjective sensation with a biological basis, using a stepwise discovery, prioritization, validation, and testing in independent cohorts design. We studied psychiatric patients, a high risk group for co-morbid pain disorders and increased perception of pain. For discovery, we used a powerful withinsubject longitudinal design. We were successful in identifying blood gene expression biomarkers that were predictive of pain state, and of future emergency department (ED) visits for pain, more so when personalized by gender and diagnosis. MFAP3, which had no prior evidence in the literature for involvement in pain, had the most robust empirical evidence from our discovery and validation steps, and was a strong predictor for pain in the independent cohorts, particularly in females and males with PTSD. Other biomarkers with best overall convergent functional evidence for involvement in pain were GNG7, CNTN1, LY9, CCDC144B, and GBP1. Some of the individual biomarkers identified are targets of existing drugs. Moreover, the biomarker gene expression signatures were used for bioinformatic drug repurposing analyses, yielding leads for possible new drug candidates such as SC-560 (an NSAID), and amoxapine (an antidepressant), as well as natural compounds such as pyridoxine (vitamin B6), cyanocobalamin (vitamin B12), and apigenin (a plant flavonoid). Our work may help mitigate the diagnostic and treatment dilemmas that have contributed to the current opioid epidemic.
\end{abstract}

\section{Introduction}

"The greatest evil is physical pain"

- Saint Augustine

Supplementary information The online version of this article (https:// doi.org/10.1038/s41380-018-0345-5) contains supplementary material, which is available to authorized users.

A. B. Niculescu

anicules@iupui.edu

1 Department of Psychiatry, Indiana University School of Medicine, Indianapolis, IN, USA

2 Stark Neuroscience Research Institute, Indiana University School of Medicine, Indianapolis, IN, USA

3 Indianapolis VA Medical Center, Indianapolis, IN, USA

4 Department of Molecular and Experimental Medicine, The Scripps Research Institute, La Jolla, CA, USA

5 Department of Anesthesia, Indiana University School of Medicine, Indianapolis, IN, USA
Pain is a subjective feeling with objective roots and profound evolutionary biological utility. It reflects perceived or actual damage to the organism [1,2]. Mental states can affect the perception of pain, and in turn be affected by pain. Psychiatric patients may have an increased perception of pain, as well as increased physical health reasons for pain, due to their often adverse life trajectory [3]. As such, they may be a particularly suitable population in which to try to identify peripheral blood biomarkers for pain, that may be complementary to genetic findings in the field [4]. Of note, a number of psychiatric medications are currently used to treat pain disorders [5]. Given these close inter-relationships, we expect our findings to be generalizable, trans-diagnostic, and have general relevance to pain, independent of specific psychiatric disorders.

First, we used a powerful longitudinal within-subject design in individuals with psychiatric disorders to discover blood gene expression changes between self-reported low pain and high pain states. Second, we prioritized the list of candidate biomarkers with a Bayesian-like Convergent Functional Genomics approach, comprehensively 
integrating previous published human and animal model evidence in the field for involvement in pain, and directly citing it. Third, we validated our top biomarkers from discovery and prioritization in an independent cohort of psychiatric subjects with a clinical diagnosis of a pain disorder and with high scores on pain severity and functional impact ratings. Fourth, we tested if the candidate biomarkers from the first three steps are able to predict high pain state, and future emergency department (ED) visits for pain, in another independent cohort of psychiatric subjects. We tested the biomarkers in all subjects in the independent test cohort, as well as in a more personalized fashion by gender and psychiatric diagnosis, showing increased accuracy with the personalized approach. Fifth, we assessed if our biomarkers have evidence for involvement in other psychiatric and related disorders, as well as analyzed the biological pathways and networks they are involved in. Sixth, we bioinformatically identified which of our individual biomarkers are modulated by existing drugs and thus can be used for pharmacogenomic population stratification and measuring of response to treatment, as well as used the gene expression signatures of the top predictive biomarkers to interrogate the Connectivity Map database from Broad/MIT to identify drugs and natural compounds that could be repurposed for treating pain.

\section{Materials and methods}

\section{Cohorts}

We used three independent cohorts: discovery (major psychiatric disorders), validation (major psychiatric disorders with clinically severe pain disorders), and testing (an independent major psychiatric disorders cohort for predicting pain state, and for predicting future ED visits for pain) (Fig. 1a).

Similar to our previous studies [6-8], the psychiatric subjects are part of a larger longitudinal cohort of adults that we are continuously collecting. Subjects were recruited from the patient population at the Indianapolis VA Medical Center. All subjects understood and signed informed consent forms detailing the research goals, procedure, caveats and safeguards, per Indiana University IRB approved protocol. Subjects completed diagnostic assessments by an extensive structured clinical interview -Diagnostic Interview for Genetic Studies, and up to six testing visits, 3-6 months apart or whenever a new psychiatric hospitalization occurred. At each testing visit, they received a series of rating scales, including a visual analog scale (1-10) for assessing pain and the SF 36 quality of life scale, which has two pain-related items (items 21 and 22), and the blood was drawn. We collected whole blood $(10 \mathrm{ml})$ in two RNA-stabilizing PAXgene tubes, labeled with an anonymized ID number, and stored at $-80{ }^{\circ} \mathrm{C}$ in a locked freezer until the time of future processing. Whole-blood RNA was extracted for microarray gene expression studies from the PAXgene tubes, as detailed below.

For this study, our within-subject discovery cohort, from which the biomarker data were derived, consisted of 28 subjects (19 males, 9 females) with multiple testing visits, who each had at least one diametric change in pain from Low Pain (VAS of 2 and below) to High Pain (VAS of 6 and above) from one testing visit to another (Fig. $1 \mathrm{~b}$ and Fig. S1). There were three subjects with five visits each, one subject with four visits, twelve subjects with three visits each, and twelve subjects with two visits each resulting in a total of 79 blood samples for subsequent gene expression microarray studies (Fig. 1 and Table S1).

Our validation cohort, in which the top biomarker findings were validated for being even more changed in expression, consisted of 13 male and 10 female subjects with a pain disorder diagnosis and clinically severe pain (Table S1). This was determined as having a pain VAS of 6 and above and a sum of SF36 scale items 21 (pain intensity) and 22 (impairment by pain of daily activities) of 10 and above (Table S1).

Our independent test cohort for predicting state (High Pain) consisted of 134 male and 28 female subjects with psychiatric disorders, demographically matched with the discovery cohort, with one or multiple testing visits in our lab, with either Low Pain, intermediate Pain, or High Pain, resulting in a total of 414 blood samples in which wholegenome blood gene expression data were obtained (Fig. 1 and Table S1).

Our test cohort for predicting trait (future ED visits with pain as the primary reason in the first year of follow-up, and all future ED visits for pain) (Fig. 1) consisted of 171 males and 19 female subjects for which we had longitudinal follow-up with electronic medical records. The subjects' subsequent number of ED pain-related visits in the year following testing was tabulated from electronic medical records by a clinical researcher, who used the key word "pain" in the reasons for ED visit, or "ache" with a mention of acute pain in the text of the note.

\section{Medications}

The subjects in the discovery cohort were all diagnosed with various psychiatric disorders, and had various medical co-morbidities (Table 1). Their medications were listed in their electronic medical records, and documented by us at the time of each testing visit. Medications can have a strong influence on gene expression. However, our discovery of 
A

(Within-Subject Changes in Pain State)

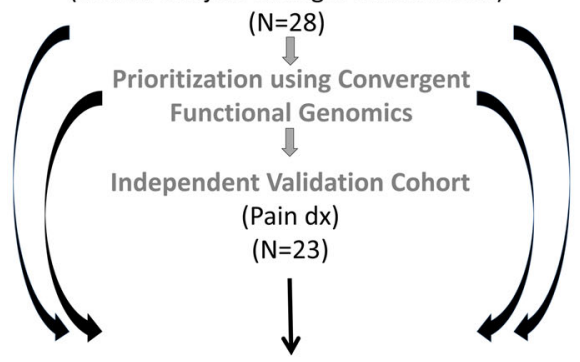

Independent Testing Cohorts for Predictions State Pain ( $\mathrm{N}=162)$

Trait Future ED Visits for Pain ( $N=189)$

D
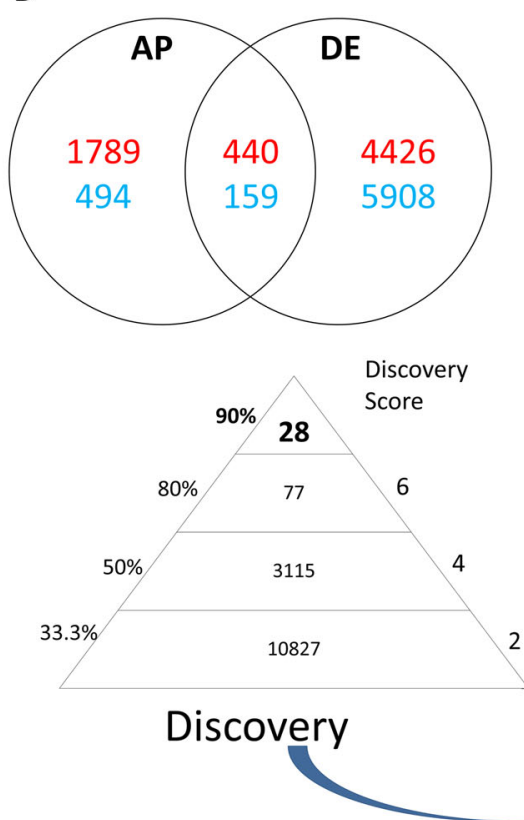

Fig. 1 Steps 1-3: Discovery, prioritization, and validation. a Cohorts used in study, depicting flow of discovery, prioritization, and validation of biomarkers from each step. b Discovery cohort longitudinal within-subject analysis. Phchp\#\#\# is study ID for each subject. V\# denotes visit number. c Discovery of possible subtypes of Pain based on High Pain visits in the discovery cohort. Subjects were clustered using measures of mood and anxiety (Simplified Affective State Scale (SASS)), as well as psychosis (PANNS Positive). d Differential gene expression in the Discovery cohort-number of genes identified with differential expression (DE) and absent-present (AP) methods with an internal score of 2 and above. Red-increased in expression in High Pain, blue-decreased in expression in High Pain. At the discovery step probesets are identified based on their score for tracking pain with a maximum of internal points of $6(33 \%$ (2 pt), 50\% (4 pt), and $80 \%$

differentially expressed genes was based on within-subject analyses, which factor out not only genetic background effects but also minimizes medication effects, as the subjects rarely had major medication changes between visits.
C
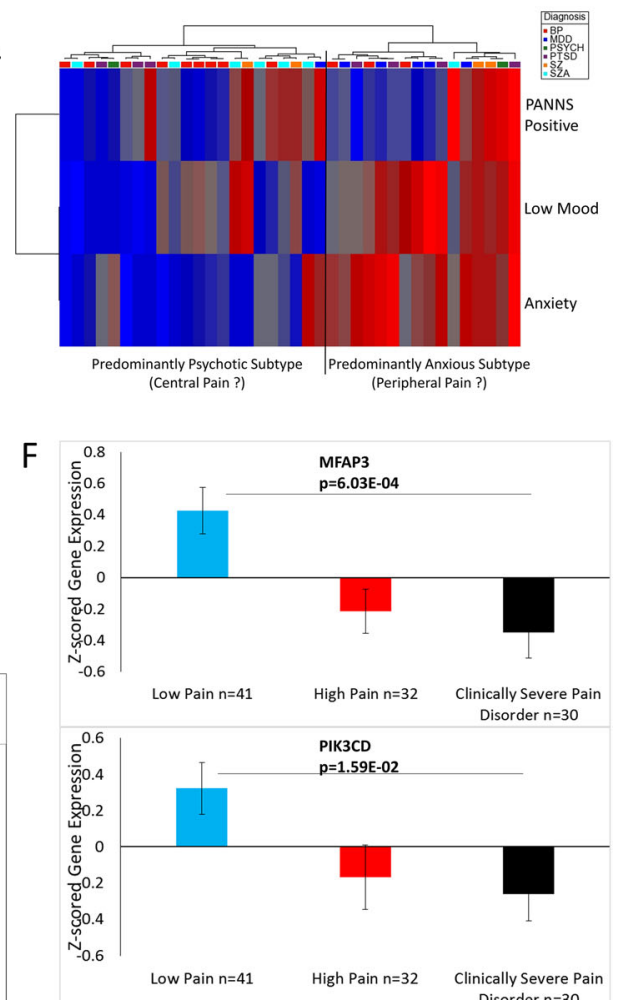

Low Pain $n=41 \quad$ High Pain $n=32 \quad$ Clinically Severe Pain

Validation

Prioritization

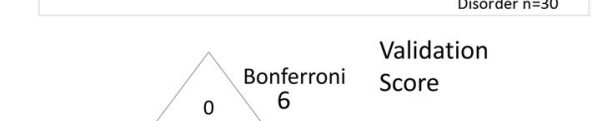


Table 1 Aggregate Demographics

\begin{tabular}{|c|c|c|c|c|c|c|}
\hline Cohorts & $\begin{array}{l}\text { Number of } \\
\text { subjects }\end{array}$ & Gender & Diagnosis & Ethnicity & $\begin{array}{l}\text { Age at } \\
\text { time of } \\
\text { visit } \\
\text { Mean } \\
\text { (SD) }\end{array}$ & T-test for age \\
\hline \multicolumn{7}{|l|}{ Discovery } \\
\hline $\begin{array}{l}\text { Discovery cohort (longitudinal } \\
\text { withinsubject changes in pain } \\
\text { scale }(1-10) \text { ) Low Pain 0-2 to } \\
\text { High Pain 6-10 }\end{array}$ & $\begin{array}{l}28 \text { (with } 79 \\
\text { visits) }\end{array}$ & $\begin{array}{l}\text { Male }=19 \\
\text { Female }=9\end{array}$ & $\begin{array}{l}\mathrm{BP}=9 \\
\mathrm{MDD}=3 \\
\mathrm{SZA}=6 \\
\mathrm{SZ}=3 \\
\mathrm{PTSD}=5 \\
\mathrm{PSYCH}=2\end{array}$ & $\begin{array}{l}\mathrm{EA}=17 \\
\mathrm{AA}=10 \\
\text { Mixed }=1\end{array}$ & $52(7.94)$ & \\
\hline \multicolumn{7}{|l|}{ Validation } \\
\hline $\begin{array}{l}\text { Independent validation cohort } \\
\text { (clinical Severe pain diagnosis } \\
\text { SF36 sum of scores on } \\
\text { questions } 21 \text { and } 22 \geq 10 \text { Pain } \\
\text { scale } \geq 6 \text { ) }\end{array}$ & $\begin{array}{l}23 \text { (30 } \\
\text { visits) }\end{array}$ & $\begin{array}{l}\text { Male }=13 \\
\text { Female }=10\end{array}$ & $\begin{array}{l}\mathrm{MDD}=8 \\
\mathrm{BP}=6 \\
\mathrm{SZ}=2 \\
\mathrm{SZA}=2 \\
\mathrm{PTSD}=2 \\
\mathrm{MOOD}=3\end{array}$ & $\begin{array}{l}\mathrm{EA}=17 \\
\mathrm{AA}=6\end{array}$ & $51.9(7.1)$ & \\
\hline \multicolumn{7}{|l|}{ Testing } \\
\hline $\begin{array}{l}\text { Independent testing cohort for } \\
\text { predicting State (High Pain } \\
\text { State Pain Scale } \geq 6 \text { at time of } \\
\text { assessment) }\end{array}$ & $\begin{array}{l}162(411 \\
\text { visits) }\end{array}$ & $\begin{array}{l}\text { Male }=134 \\
\text { Female }=28\end{array}$ & $\begin{array}{l}\mathrm{BP}=52 \\
\mathrm{MDD}=39 \\
\mathrm{SZA}=19 \\
\mathrm{SZ}=26 \\
\mathrm{PTSD}=20 \\
\mathrm{MOOD}=4 \\
\mathrm{PSYCH}=2\end{array}$ & $\begin{array}{l}\mathrm{EA}=112 \\
\mathrm{AA}=48 \\
\text { Hispanic }=2\end{array}$ & $\begin{array}{l}50.3 \\
(8.97) \\
\text { Others } \\
50.12 \\
\text { High Pain } \\
50.50\end{array}$ & $\begin{array}{l}\text { High Pain }(\mathrm{n}=101) \\
\text { Vs. Others } \\
(\mathrm{n}=310) \\
\mathbf{0 . 8 2 4}\end{array}$ \\
\hline $\begin{array}{l}\text { Independent testing cohort for } \\
\text { predicting trait (Future ED } \\
\text { visits for pain in the first year } \\
\text { following assessment) }\end{array}$ & $\begin{array}{l}181 \text { (470 } \\
\text { visits) }\end{array}$ & $\begin{array}{l}\text { Male }=163 \\
\text { Female }=18\end{array}$ & $\begin{array}{l}\mathrm{BP}=46 \\
\mathrm{MDD}=33 \\
\mathrm{SZA}=45 \\
\mathrm{SZ}=38 \\
\mathrm{PTSD}=13 \\
\mathrm{MOOD}=4 \\
\mathrm{PSYCH}=2\end{array}$ & $\begin{array}{l}\mathrm{EA}=117 \\
\mathrm{AA}=62 \\
\text { Hispanic }=2\end{array}$ & $\begin{array}{l}52.45 \\
(6.13) \\
\text { Others } \\
52.61 \mathrm{ED} \\
\text { visits for } \\
\text { Pain } \\
51.87\end{array}$ & $\begin{array}{l}\text { ED visits for Pain } \\
(\mathrm{n}=102) \text { vs. Others } \\
(\mathrm{n}=368) \\
\mathbf{0 . 2 3 7}\end{array}$ \\
\hline $\begin{array}{l}\text { Independent testing cohort for } \\
\text { predicting trait (Future ED } \\
\text { visits for pain in All Years } \\
\text { following assessment) }\end{array}$ & $\begin{array}{l}189 \text { (501 } \\
\text { visits) }\end{array}$ & $\begin{array}{l}\text { Male }=170 \\
\text { Female }=19\end{array}$ & $\begin{array}{l}\mathrm{BP}=49 \\
\mathrm{MDD}=34 \\
\mathrm{SZA}=45 \\
\mathrm{SZ}=40 \\
\mathrm{PTSD}=15 \\
\mathrm{MOOD}=4 \\
\mathrm{PSYCH}=2\end{array}$ & $\begin{array}{l}\mathrm{EA}=124 \\
\mathrm{AA}=62 \\
\text { Hispanic }=3\end{array}$ & $\begin{array}{l}51.79 \\
(6.75) \\
\text { Others } \\
51.58 \text { ED } \\
\text { visits for } \\
\text { Pain } \\
52.02\end{array}$ & $\begin{array}{l}\text { ED visits for Pain } \\
(\mathrm{n}=239) \text { vs. Others } \\
(\mathrm{n}=262) \\
\mathbf{0 . 4 7 2 0}\end{array}$ \\
\hline
\end{tabular}

MDD depression, BP bipolar, SZ schizophrenia, SZA schizoaffective, PSYCHOSIS schizophrenia and schizoaffective combined, PTSD posttraumatic stress disorder

and may thus have changes in medications or drug of abuse not reflected in their medical records. That being said, our goal is to find biomarkers that track pain, regardless if the reason for it is endogenous biology or driven by substance abuse or medication non-compliance. In fact, one would expect some of these biomarkers to be targets of medications, as we show in this paper. Overall, the discovery of biomarkers with our universal design occurs despite the subjects having different genders, diagnoses, being on various different medications, and other lifestyle variables.

\section{Blood gene expression experiments}

\section{RNA extraction}

Whole blood $(2.5-5 \mathrm{ml})$ was collected into each PaxGene tube by routine venipuncture. PaxGene tubes contain proprietary reagents for the stabilization of RNA. RNA was extracted and processed as previously described [6-8].

\section{Microarrays}

Microarray work was carried out using previously described methodology [6-9]. and as described below.

\section{Biomarkers}

\section{Step 1: Discovery}

We have used the subject's score from the VAS Pain Scale, assessed at the time of blood collection (Fig. 1). We analyzed gene expression differences between visits with Low Pain (defined as a score of 0-2) and visits with High Pain (defined as a score of 6 and above), using a powerful 
within-subject design, then an across-subjects summation (Fig. 1).

We analyzed the data in two ways: an Absent-Present (AP) approach, and a differential expression (DE) approach, as in previous work by us on suicide biomarkers [6-8]. The AP approach may capture turning on and off of genes, and the DE approach may capture gradual changes in expression. Analyses were performed as previously described [7-9]. We have developed in our labs R scripts to automate and conduct all these large dataset analyses in bulk, checked against human manual scoring [9].

Gene Symbol for the probesets were identified using NetAffyx (Affymetrix) for Affymetrix HG-U133 Plus 2.0 GeneChips, followed by GeneCards to confirm the primary gene symbol. In addition, for those probesets that were not assigned a gene symbol by NetAffyx, we used GeneAnnot (https://genecards.weizmann.ac.il/geneannot/index.shtml) to obtain gene symbols for these uncharacterized probesets, followed by GeneCard. Genes were then scored using our manually curated CFG databases as described below (Fig. 1e).

\section{Step 2: Prioritization using Convergent Functional Genomics (CFG)}

Databases: We have established in our laboratory (Laboratory of Neurophenomics, www.neurophenomics. info) manually curated databases of the human gene expression/protein expression studies (postmortem brain, peripheral tissue/fluids: CSF, blood and cell cultures), human genetic studies (association, copy number variations and linkage), and animal model gene expression and genetic studies, published to date on psychiatric disorders. Only findings deemed significant in the primary publication, by the study authors, using their particular experimental design and thresholds, are included in our databases. Our databases include only primary literature data and do not include review papers or other secondary data integration analyses to avoid redundancy and circularity. These large and constantly updated databases have been used in our CFG cross validation and prioritization platform (Fig. 1e). For this study, data from 355 papers on pain were present in the databases at the time of the CFG analyses (December 2017) (human genetic studies-212, human nervous tissue studies3 , human peripheral tissue/fluids- 57, non-human genetic studies-26, non-human brain/nervous tissue studies-48, non-human peripheral tissue/fluids- 9). Analyses were performed as previously described [7, 8].

\section{Step 3: Validation analyses}

Validation analyses of our candidate biomarker genes were conducted separately for AP and for DE. We examined which of the top candidate genes (total CFG score of 6 or above), were stepwise changed in expression from the Low Pain and High Pain group to the Clinically Severe Pain group. A CFG score of 6 or above reflects an empirical cutoff of $33.3 \%$ of the maximum possible CFG score of 12 , which permits the inclusion of potentially novel genes with maximal internal score of 6 but no external evidence score. Subjects with Low Pain, as well as subjects with High Pain from the discovery cohort who did not have severe clinical pain (SF36 sum of item 21 and $22<10$ ) were used, along with the independent validation cohort which all had severe clinical pain and a co-morbid pain disorder diagnosis $(n=23)$.

For the AP analyses, we imported the Affymetrix microarray.chp data files from the subjects in the validation cohort of Clinically Severe Pain into MAS5 Affymetrix Expression Console, alongside the data files from the Low Pain and High Pain groups in the live discovery cohort. We transferred the AP data to an Excel sheet and transformed $A$ into $0, M$ into 0.5 , and $P$ into 1 . We then $Z$-scored everything together by gender and diagnosis. If a probeset would have showed no variance and thus gave a non-determined $(0 / 0)$ value in $Z$-scoring in a gender and diagnosis, we would have excluded the values from that probeset for that gender and diagnosis from the analysis.

For the DE analyses, the cohorts (Validation Clinically Severe Pain, alongside the Low Pain and High Pain groups in the Discovery cohort) were assembled out of Affymetrix .cel data that was RMA normalized by gender and diagnosis. We transferred the log transformed expression data to an Excel sheet, and non-log transformed the data by taking 2 to the power of the transformed expression value. We then $Z$-scored the values by gender and diagnosis.

We then imported the Excel sheets with the Z-scored by gender and diagnosis AP and DE expression data into Partek, and statistical analyses were performed using a oneway ANOVA for the stepwise changed probesets, and also attempted a stringent Bonferroni corrections for all the probesets tested (Figure 1F). We also wrote an R script that automatically analyzes the data directly from the Excel sheet, and used that to confirm our calculations.

\section{Choice of biomarkers to be carried forward}

We carried forward into testing the top biomarkers from each step. The longer list of candidate biomarkers includes the top biomarkers from discovery step $(\geq 90 \%$ of scores, $n=28$ ), the top biomarkers from the prioritization step (CFG score $\geq 8, n=32$ ), and the nominally significant biomarkers after the validation step $(n=5)$, for a total of $n=65$ probesets ( $n=60$ genes). The short list of top biomarkers after the validation step is five biomarkers. In Step 4, testing, we then predict with the biomarkers 
from the long list in independent cohorts High Pain state, and future ED visits for pain in the first year, and in all future years.

\section{Diagnostics}

The test cohort for predicting High Pain (state), and the subset of it that is a test cohort for predicting future ED visits (trait), were assembled out of data that was RMA normalized by gender and diagnosis. The cohort was completely independent, there was no subject overlap with the discovery cohort. Phenomic (clinical) and gene expression markers used for predictions were $Z$-scored by gender and diagnosis, to be able to combine different markers into panels and to avoid potential artefacts due to different ranges of expression in different gender and diagnoses. Markers were combined by simple summation of the increased risk markers minus the decreased risk markers. Predictions were performed using R-studio.

\section{Predicting state-high pain state}

Receiver-operating characteristic (ROC) analyses between genomic and phenomic marker levels and Pain were performed by assigning subjects with a Pain score of 6 and greater into the High Pain category. We used the pROC package of R (Xavier Robin et al. BMC Bioinformatics 2011). We used the $Z$-scored biomarker and phene scores, running them in this ROC generating program against the diagnostic groups in the independent test cohort (High Pain vs. the rest of subjects). Additionally, a one-tailed t-test was performed between High Pain group vs. the rest, and Pearson R (one-tail) was calculated between Pain scores and marker levels (Supplementary InformationComplete Datasets and Analyses).

\section{Predicting trait-future ED visits for pain in first year following testing}

We conducted analyses for predicting ED visits for pain in the first year following each testing visit, in subjects that had at least 1 year of follow-up in the VA system, for which we have access to complete electronic medical records. ROC analyses between genomic and phenomic marker levels at a specific testing visit and future ED visits for pain were performed as described above, based on assigning if subjects had visited the ED with primary reason for pain or not within 1 year following a testing visit. Additionally, a one tailed $t$-test with unequal variance was performed between groups of subject visits with and without ED visits for Pain. Pearson R (one-tail) correlation was performed between hospitalization frequency (number of ED visits for Pain divided by duration of follow-up) and marker levels. A Cox regression was performed using the time in days from the testing visit date to first ED visit date in the case of patients who had been to the ED, or 365 days for those who did not. The hazard ratio was calculated such that a value $>1$ always indicates increased risk for ED visits, regardless if the biomarker is increased or decreased in expression.

We also conducted odds ratio analyses for ED visits for pain for all future ED visits due to pain, including those occurring beyond 1 year of follow-up, in the years following testing (on average 5.56 years per subject, range 0.44 to 11.27 years; see Table 1 and Table S1), as this calculation, unlike the ROC and $t$-test, accounts for the actual length of follow-up, which varied from subject to subject. The ROC and $t$-test might in fact, if used, under-represent the power of the markers to predict, as the more severe psychiatric patients are more likely to move geographically and/or be lost to follow-up. A Cox regression was also performed using the time in days from visit date to first ED Pain visit date in the case of patients who had been to the ED for Pain, or from visit date to last note date in the electronic medical records for those who did not. The hazard ratio was calculated such that a value $>1$ always indicates increased risk for ED Pain-related visits, regardless if the biomarker is increased or decreased in expression.

\section{Biological understanding}

\section{Pathway analyses}

IPA (Ingenuity Pathway Analyses, version 24390178, Qiagen), David Functional Annotation Bioinformatics Microarray Analysis (National Institute of Allergy and Infectious Diseases) version 6.7 (August 2016), and Kyoto Encyclopedia of Genes and Genomes (KEGG) (through DAVID) were used to analyze the biological roles, including top canonical pathways and diseases (Table S4), of the candidate genes resulting from our work, as well as to identify genes in our dataset that are the target of existing drugs. We ran the pathway analyses for the combined AP and DE probesets 60 unique genes (65 probesets). For Network analysis of the 60 unique genes we performed STRING Interaction Network (https://string-db.org) by in putting the genes into the search window and performed Multiple Proteins Homo sapiens analysis.

\section{CFG beyond Pain: evidence for involvement in other psychiatric and related disorders}

We also used a CFG approach to examine evidence from other psychiatric and related disorders, for the long list of 65 candidate biomarkers (Table S3). 


\section{Therapeutics}

\section{Pharmacogenomics}

We analyzed which of our individual top biomarkers is known to be modulated by existing drugs using our CFG databases, and using Ingenuity Drugs analyses (Table S4).

\section{New drug discovery/repurposing}

We also analyzed which drugs and natural compounds are an opposite match for the gene expression profile of panels of our top biomarkers $(n=65)$, using the Connectivity Map (https://portals.broadinstitute.org, Broad Institute, MIT) (Table 3). Thirty-three out of 65 probesets were present in the HGU-133A array used for the Connectivity Map.

\section{Convergent functional evidence (CFE)}

We tabulated into a convergent functional evidence (CFE) score all the evidence from discovery (up to 6 points), prioritization (up to 12 points), validation (up to 6 points), testing (state, trait first year ED visits, trait all future ED visits- up to 8 points each if significantly predicts in all subjects, 6 points if predicts by gender, 4 points if predicts in gender/diagnosis). The total score can be up to 48 points: 36 from our data and 12 from literature data. We weigh our data three times as much as the literature data. The goal is to highlight, based on the totality of our data and of the evidence in the field to date, biomarkers that have all around evidence: track pain, are reflective of pain pathology, and predict it. Such biomarkers merit priority evaluation in future clinical trials.

\section{Results}

First, we used a discovery cohort composed of subjects with psychiatric disorders followed longitudinally over time [611], in which each subject had blood samples collected and neuropsychological testing done in at least one low pain state visit (Pain VAS $\leq 2$ out of 10 ) and at least one high pain state visit (Pain VAS $\geq 6$ out of 10) (Fig. 1 and Fig. S1).

We used a powerful longitudinal within-subject design [6-12] in individuals to discover blood gene expression changes between self-reported low pain and high pain states. A longitudinal within-subject design is orders of magnitude more powerful than a cross-sectional case-control design. Some of these candidate gene expression biomarkers are increased in expression in high pain states (being putative risk genes, or "algogenes"), and others are decreased in expression (being putative protective genes, or "pain suppressor genes").

Second, we prioritized this list of candidate biomarkers with a Bayesian-like Convergent Functional Genomics approach [13, 14], comprehensively integrating previous published human and animal model evidence in the field for involvement in pain, and directly citing it.

Third, we further validated our top biomarkers from discovery and prioritization in an independent cohort of psychiatric subjects also carrying a clinical diagnosis of a pain disorder, and with high scores on pain severity and functional impairment ratings.

We ended up with a list of 65 candidate biomarkers (Table 2 and S2, S3, S5) from the first three steps, including a shorter list of five validated biomarkers (MFAP3, PIK3CD, SVEP1, TNFRSF11B, ELAC2). The biomarkers with the best evidence after validation were Hs.666804/ MFAP3 ( $p=6.03 \mathrm{E}-04)$ and PIK3CD $(p=1.59 \mathrm{E}-02)$.

Fourth, we tested if the 65 candidate biomarkers are able to predict pain severity state, and future emergency department (ED) visits for pain, in another independent cohort of psychiatric subjects. We used biomarker levels information crosssectionally, as well as expanded longitudinal information about biomarker levels at multiple visits, as predictors. We tested the biomarkers in all subjects in the test cohort, as well as in a more personalized fashion by gender and psychiatric diagnosis, showing increased accuracy with the personalized approach, in particular in women (Fig. 2). Across all subjects tested, CNTN1 was the best predictor for state (AUC 63\%, $p=0.0014)$, GBP1 the best predictor for trait first year ED visits (AUC 59\%, $p=0.0035$ ), and GNG7 the best predictor for trait all future ED visits (OR 1.28, $p=0.00013$, surviving Bonferroni correction for the 65 biomarkers tested). By gender, in females, DNAJC18 was the best predictor for state (AUC 78\%, $p=0.0049$ ), GBP1 the best predictor for trait first year ED visits (AUC 71\%, $p=0.043$ ) and ASTN2 for trait all future $\mathrm{ED}$ visits (OR 2.45, $p=0.044)$. In males, CNTN1 was the best predictor for state (AUC 63\%, $p=$ 0.0022), Hs.554262 the best predictor for trait first year ED visits (AUC 59\%, $p=0.016$ ), and MFAP3 the best predictor for trait all future ED visits (OR 1.35, $p=0.0089$ ). Personalized by gender and diagnosis, in female bipolar CDK6 was a strong predictor for state (AUC 100\%, $p=0.007$ ), in female PTSD SHMT1 was a strong predictor for trait first year ED visits (AUC $100 \%, p=0.022$ ), and in female depression GNG7 for trait all future ED visits (OR 14.54, $p=0.022$ ). In male depression CASP6 was a strong predictor for state (AUC 87\%, $p=0.00007$, surviving Bonferroni correction for the 65 biomarkers tested), in male PTSD LY9 was a strong predictor for trait first year ED visits (AUC 77\%, $p=0.041$ ), and in male PTSD MFAP3 was a strong predictor for trait all future $\mathrm{ED}$ visits (OR 15.93, $p=0.00085)$. In general, panels of all 65 top biomarkers or of the five validated biomarkers 
Table 2 Convergent functional evidence (CFE) for top candidate biomarkers for pain ( $n=60$ genes, 65 probesets)

\begin{tabular}{|c|c|c|c|c|c|c|c|c|c|c|}
\hline $\begin{array}{l}\text { Gene symbol/gene } \\
\text { name }\end{array}$ & Probesets & $\begin{array}{l}\text { Step } 1 \\
\text { Discovery } \\
\text { in blood } \\
\text { (direction } \\
\text { of change) } \\
\text { Method/ } \\
\text { score/\% } \\
\text { Up to } 6 \text { pts }\end{array}$ & $\begin{array}{l}\text { Step } 2 \\
\text { External } \\
\text { convergent } \\
\text { functional } \\
\text { genomics } \\
\text { (CFG) } \\
\text { Evidence for } \\
\text { involvement } \\
\text { in pain score } \\
\text { Up to } 12 \text { pts }\end{array}$ & $\begin{array}{l}\text { Step } 3 \\
\text { Validation } \\
\text { in blood } \\
\text { ANOVA } \\
p \text {-value/ } \\
\text { score Up } \\
\text { to } 6 \text { pts }\end{array}$ & $\begin{array}{l}\text { Step } 4 \\
\text { Best significant } \\
\text { prediction of } \\
\text { State-High Pain } \\
\text { (Cases/Total) } \\
\text { ROC AUC/ } \\
\text { p-value } \\
8 \text { pts All } \\
6 \text { pts Gender } \\
4 \text { pts Gender/Dx }\end{array}$ & $\begin{array}{l}\text { Step } 4 \\
\text { Best Significant } \\
\text { prediction of } \\
\text { Trait-Future ED } \\
\text { visits for Pain in } \\
\text { the first year } \\
\text { (Cases/Total) } \\
\text { ROC AUC/ } \\
p \text {-value } \\
8 \text { pts All } \\
6 \text { pts Gender } \\
4 \text { pts Gender/Dx }\end{array}$ & $\begin{array}{l}\text { Step } 4 \\
\text { Best significant predictions } \\
\text { of Trait- Future ED visits for } \\
\text { Pain in all future years } \\
\text { (Cases/Total) } \\
\text { OR/OR p-value } \\
8 \text { pts All } \\
6 \text { pts Gender } \\
4 \text { pts Gender/Dx }\end{array}$ & $\begin{array}{l}\text { Step } 5 \\
\text { Other psychiatric } \\
\text { and related } \\
\text { disorders evidence }\end{array}$ & $\begin{array}{l}\text { Step } 6 \\
\text { Drugs That } \\
\text { Modulate the } \\
\text { Biomarker in } \\
\text { opposite } \\
\text { Direction to } \\
\text { Pain }\end{array}$ & $\begin{array}{l}\text { CFE } \\
\text { Polyevidence } \\
\text { score for } \\
\text { involvement in } \\
\text { pain (based on } \\
\text { steps 1-4) }\end{array}$ \\
\hline $\begin{array}{l}G N G 7 \\
\text { G Protein subunit } \\
\text { gamma } 7\end{array}$ & 1566643_a_at & $\begin{array}{l}\text { (D) } \\
\mathrm{DE} / 459 \%\end{array}$ & 6 & $\begin{array}{l}6.81 \mathrm{E}-02 / 2 \\
\text { Stepwise }\end{array}$ & $\begin{array}{l}\text { All } \\
\text { C:(101/411) } \\
0.56 / 3.52 \mathrm{E}-02 \\
\text { Gender } \\
\text { Male } \\
\text { C:(85/346) } \\
0.56 / 3.95 \mathrm{E}-02 \\
\text { Gender/Dx } \\
\text { M-SZ } \\
\text { C:(11/64) } \\
0.68 / 2.79 \mathrm{E}-02\end{array}$ & $\begin{array}{l}\text { Gender } \\
\text { Females } \\
\text { C:(7/44) } \\
0.7 / 4.92 \mathrm{E}-02 \\
\text { Gender/Dx } \\
\text { F-MDD } \\
\text { C:(4/11) } \\
0.82 / 4.45 \mathrm{E}-02 \\
\text { L:(2/6) } \\
\text { 1/3.20E-02 } \\
\text { F-PTSD } \\
\text { C:(2/8) } \\
0.92 / 4.78 \mathrm{E}-02\end{array}$ & $\begin{array}{l}\text { All } \\
\text { C:(239/501) } \\
1.28 / 1.03 E-04 \\
\text { L:(145/309) } \\
1.22 / 1.70 \mathrm{E}-02 \\
\text { Gender } \\
\text { Females } \\
\text { C:(13/47) } \\
1.69 / 4.69 \mathrm{E}-02 \\
\text { Males } \\
\text { C:(226/454) } 1.28 / \mathbf{1 . 9 2 E - 0 4}{ }^{\mathrm{a}} \\
\text { L:(138/282) } 1.21 / 2.16 \mathrm{E}-02 \\
\text { Gender/Dx } \\
\text { F-MDD } \\
\text { C:(4/12) } \\
14.54 / 2.23 \mathrm{E}-02 \\
\text { M-MDD } \\
\text { L:(25/43) } \\
1.8 / 2.70 \mathrm{E}-02 \\
\text { M-PSYCHOSIS } \\
\text { C:(95/201) } \\
1.52 / 1.70 \mathrm{E}-\mathbf{0 4} 4^{\mathrm{a}} \\
\text { L:(57/120) } \\
1.34 / 2.47 \mathrm{E}-02 \\
\text { M-SZ } \\
\text { C:(42/103) } \\
1.58 / 2.08 \mathrm{E}-02 \\
\text { M-SZA } \\
\text { C:(53/98) } \\
1.71 / 4.40 \mathrm{E}-04^{\mathrm{a}}\end{array}$ & $\begin{array}{l}\text { Alcohol } \\
\text { BP } \\
\text { Hallucinogens } \\
\text { MDD } \\
\text { Stress } \\
\text { SZ }\end{array}$ & $\begin{array}{l}\text { Omega-3 fatty } \\
\text { acids }\end{array}$ & 34 \\
\hline $\begin{array}{l}\text { CNTNI } \\
\text { Contactin } 1\end{array}$ & 1554784_at & $\begin{array}{l}\text { (D) } \\
\mathrm{DE} / 452 \%\end{array}$ & 6 & NS & $\begin{array}{l}\text { All } \\
\text { C:(101/411) } \\
0.58 / 1.15 \mathrm{E}-02 \\
\text { L:(61/248) } \\
0.63 / 1.42 \mathrm{E}-03 \\
\text { Gender } \\
\text { Female } \\
\text { C:(16/65) } \\
0.65 / 3.38 \mathrm{E}-02 \\
\text { Male } \\
\text { L:(51/212) } \\
0.63 / 2.27 \mathrm{E}-03 \\
\text { Gender/Dx } \\
\text { M-BP } \\
\text { C:(24/123) } \\
0.61 / 4.13 \mathrm{E}-02 \\
\text { L:(16/81) } \\
0.64 / 4.06 \mathrm{E}-02 \\
\text { M-SZ } \\
\text { C:(11/64) } \\
0.68 / 3.15 \mathrm{E}-02 \\
\text { M-MDD } \\
\text { L:(13/43) } \\
0.66 / 4.53 \mathrm{E}-02 \\
\text { M-SZA } \\
\text { L:(3/17) } 0.83 / \\
\text { 3.89E-02 }\end{array}$ & $\begin{array}{l}\text { Gender } \\
\text { Males } \\
\text { C:(95/426) } \\
0.56 / 3.08 \mathrm{E}-02\end{array}$ & $\begin{array}{l}\text { Gender/Dx } \\
\text { M-MDD } \\
\text { C:(42/72) } \\
1.44 / 1.23 \mathrm{E}-02 \\
\text { L:(25/43) } \\
1.64 / 4.17 \mathrm{E}-02\end{array}$ & $\begin{array}{l}\text { BP } \\
\text { MDD } \\
\text { SZ } \\
\text { Suicide }\end{array}$ & Clozapine & 28 \\
\hline $\begin{array}{l}\text { LY9 } \\
\text { Lymphocyte } \\
\text { antigen } 9\end{array}$ & 231124_x_at & $\begin{array}{l}\text { (I) } \\
\mathrm{DE} / 690 \%\end{array}$ & 2 & NS & $\begin{array}{l}\text { All } \\
\text { C:(101/411) } \\
0.56 / 4.40 \mathrm{E}-02 \\
\text { L:(61/248) } \\
0.58 / 2.39 \mathrm{E}-02 \\
\text { Gender } \\
\text { Male } \\
\text { C:(85/346) } \\
0.57 / 3.02 \mathrm{E}-02 \\
\text { L:(51/212) } \\
0.62 / 5.19 \mathrm{E}-03 \\
\text { Gender/Dx } \\
\text { M-BP } \\
\text { C:(24/123) } \\
\text { 0.63/2.66E-02 } \\
\text { F-MDD } \\
\text { C:(2/18) } \\
0.97 / 1.75 \mathrm{E}-02 \\
\text { M-MDD } \\
\text { L:(13/43) } \\
0.8 / 9.87 \mathrm{E}-04\end{array}$ & $\begin{array}{l}\text { All } \\
\text { C:(102/470) } \\
0.56 / 2.30 \mathrm{E}-02 \\
\text { Gender } \\
\text { Males } \\
\text { C:(95/426) } \\
0.59 / 2.61 \mathrm{E}-03 \\
\text { Gender/Dx } \\
\text { M-BP } \\
\text { C:(18/120) } \\
0.68 / 6.91 \mathrm{E}-03 \\
\text { M-PTSD } \\
\text { L:(10/16) } \\
0.77 / 4.13 \mathrm{E}-02\end{array}$ & $\begin{array}{l}\text { Gender/Dx } \\
\text { M-MDD } \\
\text { C:(42/72) } \\
1.65 / 3.85 \mathrm{E}-03 \\
\text { L:(25/43) } \\
\text { 1.53/3.74E-02 } \\
\text { M-PTSD } \\
\text { L:(18/20) } \\
2.07 / 6.77 \mathrm{E}-03\end{array}$ & Acute stress & $\begin{array}{l}\text { Omega-3 fatty } \\
\text { acids }\end{array}$ & 28 \\
\hline
\end{tabular}


Table 2 (continued)

\begin{tabular}{|c|c|c|c|c|c|c|c|c|c|c|}
\hline $\begin{array}{l}\text { Gene symbol/gene } \\
\text { name }\end{array}$ & Probesets & $\begin{array}{l}\text { Step 1 } \\
\text { Discovery } \\
\text { in blood } \\
\text { (direction } \\
\text { of change) } \\
\text { Method/ } \\
\text { score } \% \\
\text { Up to } 6 \text { pts }\end{array}$ & $\begin{array}{l}\text { Step } 2 \\
\text { External } \\
\text { convergent } \\
\text { functional } \\
\text { genomics } \\
\text { (CFG) } \\
\text { Evidence for } \\
\text { involvement } \\
\text { in pain score } \\
\text { Up to } 12 \text { pts }\end{array}$ & $\begin{array}{l}\text { Step } 3 \\
\text { Validation } \\
\text { in blood } \\
\text { ANOVA } \\
p \text {-value/ } \\
\text { score Up } \\
\text { to } 6 \text { pts }\end{array}$ & $\begin{array}{l}\text { Step } 4 \\
\text { Best significant } \\
\text { prediction of } \\
\text { State-High Pain } \\
\text { (Cases/Total) } \\
\text { ROC AUC/ } \\
p \text {-value } \\
8 \text { pts All } \\
6 \text { pts Gender } \\
4 \text { pts Gender/Dx }\end{array}$ & $\begin{array}{l}\text { Step } 4 \\
\text { Best Significant } \\
\text { prediction of } \\
\text { Trait-Future ED } \\
\text { visits for Pain in } \\
\text { the first year } \\
\text { (Cases/Total) } \\
\text { ROC AUC/ } \\
p \text {-value } \\
8 \text { pts All } \\
6 \text { pts Gender } \\
4 \text { pts Gender/Dx }\end{array}$ & $\begin{array}{l}\text { Step } 4 \\
\text { Best significant predictions } \\
\text { of Trait- Future ED visits for } \\
\text { Pain in all future years } \\
\text { (Cases/Total) } \\
\text { OR/OR } p \text {-value } \\
8 \text { pts All } \\
6 \text { pts Gender } \\
4 \text { pts Gender/Dx }\end{array}$ & $\begin{array}{l}\text { Step } 5 \\
\text { Other psychiatric } \\
\text { and related } \\
\text { disorders evidence }\end{array}$ & $\begin{array}{l}\text { Step } 6 \\
\text { Drugs That } \\
\text { Modulate the } \\
\text { Biomarker in } \\
\text { opposite } \\
\text { Direction to } \\
\text { Pain }\end{array}$ & $\begin{array}{l}\text { CFE } \\
\text { Polyevidence } \\
\text { score for } \\
\text { involvement in } \\
\text { pain (based on } \\
\text { steps 1-4) }\end{array}$ \\
\hline $\begin{array}{l}C C D C 144 B \\
\text { Coiled-coil domain } \\
\text { containing 144B } \\
\text { (pseudogene) }\end{array}$ & 1557366_at & $\begin{array}{l}\text { (D) } \\
\mathrm{DE} / 456 \%\end{array}$ & 6 & NS & $\begin{array}{l}\text { Gender/Dx } \\
\text { F-BP } \\
\text { C:(4/21) } \\
0.79 / 3.66 \mathrm{E}-02 \\
\text { M-PSYCHOSIS } \\
\text { C:(19/96) } \\
0.68 / 8.95 \mathrm{E}-03 \\
\text { L:(10/56) } \\
0.68 / 4.16 \mathrm{E}-02 \\
\text { M-SZA } \\
\text { L:(3/17) } \\
0.9 / 1.61 \mathrm{E}-02\end{array}$ & $\begin{array}{l}\text { Gender/Dx } \\
\text { M-MDD } \\
\text { C:(26/67) } \\
0.63 / 3.43 E-02\end{array}$ & $\begin{array}{l}\text { All } \\
\text { C:(239/501) } \\
\text { 1.23/2.27E-03 } \\
\text { Gender } \\
\text { Males } \\
\text { C:(226/454) } \\
\text { 1.23/3.34E-03 } \\
\text { Gender/Dx } \\
\text { M-PSYCHOSIS } \\
\text { C:(95/201) } \\
\text { 1.41/3.46E-03 } \\
\text { L:(57/120) } \\
\text { 1.43/1.32E-02 } \\
\text { M-SZ } \\
\text { C:(42/103) } \\
\text { 1.84/4.65E-03 } \\
\text { M-SZA } \\
\text { L:(32/56) } \\
1.47 / 3.49 \mathrm{E}-02\end{array}$ & & & 26 \\
\hline $\begin{array}{l}G B P 1 \\
\text { Guanylate binding } \\
\text { protein } 1\end{array}$ & 231578_at & $\begin{array}{l}\text { (I) } \\
\mathrm{DE} / 237 \%\end{array}$ & 6 & $\begin{array}{l}3.26 \mathrm{E}-01 / 2 \\
\text { Stepwise }\end{array}$ & & $\begin{array}{l}\text { All } \\
\text { C:(102/470) } \\
0.59 / 3.51 \mathrm{E}-03 \\
\text { Gender } \\
\text { Females } \\
\text { C:(7/44) } \\
0.71 / 4.30 \mathrm{E}-02 \\
\text { Males } \\
\text { C:(95/426) } \\
0.58 / 1.04 \mathrm{E}-02 \\
\text { Gender/Dx } \\
\text { F-MDD } \\
\text { C:(4/11) } \\
0.93 / 1.17 \mathrm{E}-02 \\
\text { M-PSYCHOSIS } \\
\text { C:(33/198) } \\
0.6 / 3.25 \mathrm{E}-02 \\
\text { M-SZA } \\
\text { C:(23/97) } \\
0.62 / 4.10 \mathrm{E}-02\end{array}$ & $\begin{array}{l}\text { All } \\
\text { C:(239/501) } \\
1.09 / 3.72 \mathrm{E}-02 \\
\text { Gender } \\
\text { Females } \\
\text { C:(13/47) } \\
\text { 1.68/2.41E-02 } \\
\text { Gender/Dx } \\
\text { F-MDD } \\
\text { C:(4/12) } \\
3.1 / 4.43 \mathrm{E}-02 \\
\text { M-SZA } \\
\text { C:(53/98) } \\
1.22 / 3.65 \mathrm{E}-02\end{array}$ & $\begin{array}{l}\text { MDD } \\
\text { PTSD } \\
\text { SZ }\end{array}$ & $\begin{array}{l}\text { Omega-3 fatty } \\
\text { acids }\end{array}$ & 26 \\
\hline $\begin{array}{l}\text { Hs. } 666804 / M F A P 3 \\
\text { Microfibril } \\
\text { associated protein } 3\end{array}$ & 240949_x_at & $\begin{array}{l}\text { (D) } \\
\mathrm{DE} / 681 \%\end{array}$ & 0 & $\begin{array}{l}6.03 E-04 / 4 \\
\text { Nominal }\end{array}$ & $\begin{array}{l}\text { Gender/Dx } \\
\text { F-PTSD } \\
\text { C:(5/12) } \\
0.8 / 4.41 \mathrm{E}-02\end{array}$ & $\begin{array}{l}\text { Gender/Dx } \\
\text { M-BP } \\
\text { L:(9/80) } \\
0.75 / 7.27 \mathrm{E}-03\end{array}$ & $\begin{array}{l}\text { All } \\
\text { L:(145/309) } \\
1.28 / 2.28 \mathrm{E}-02 \\
\text { Gender } \\
\text { Males } \\
\text { C:(226/454) } \\
1.17 / 2.64 \mathrm{E}-02 \\
\text { L:(138/282) } \\
\text { 1.35/8.94E-03 } \\
\text { Gender/Dx } \\
\text { M-BP } \\
\text { L:(34/91) } \\
\text { 2.36/4.86E-04 } \\
\text { M-PTSD } \\
\text { L:(18/20) } \\
\text { 15.93/8.46E-04 }\end{array}$ & $\begin{array}{l}\text { Alcohol } \\
\text { Suicide } \\
\text { Stress }\end{array}$ & & 26 \\
\hline $\begin{array}{l}\text { CASP6 } \\
\text { Caspase } 6\end{array}$ & 209790_s_at & $\begin{array}{l}\text { (I) } \\
\mathrm{DE} / 451 \%\end{array}$ & 4 & NS & $\begin{array}{l}\text { Gender } \\
\text { Male } \\
\text { L:(51/212) } \\
0.59 / 2.92 \mathrm{E}-02 \\
\text { Gender/Dx } \\
\text { F-MDD } \\
\text { C:(2/18) } \\
1 / 1.23 \mathrm{E}-02 \\
\text { M-MDD } \\
\text { L:(13/43) } \\
0.87 / 7.01 \mathrm{E}-05^{\text {a }}\end{array}$ & $\begin{array}{l}\text { Gender } \\
\text { Males } \\
\text { C:(95/426) } \\
0.57 / 2.54 \mathrm{E}-02 \\
\text { Gender/Dx } \\
\text { M-PSYCHOSIS } \\
\text { C:(33/198) } \\
0.6 / 2.88 \mathrm{E}-02 \\
\text { M-SZA } \\
\text { C:(23/97) } \\
0.63 / 2.71 \mathrm{E}-02\end{array}$ & $\begin{array}{l}\text { Gender/Dx } \\
\text { M-MDD } \\
\text { C:(42/72) } \\
1.31 / 3.97 \mathrm{E}-02\end{array}$ & $\mathrm{BP}$ & & 24 \\
\hline $\begin{array}{l}\text { COMT } \\
\text { Catechol-O- } \\
\text { methyltransferase }\end{array}$ & 216204_at & $\begin{array}{l}\text { (D) } \\
\mathrm{DE} / 454 \%\end{array}$ & 4 & NS & $\begin{array}{l}\text { Gender/Dx } \\
\text { M-MDD } \\
\text { L:(13/43) } \\
0.71 / 1.41 E-02\end{array}$ & $\begin{array}{l}\text { All } \\
\text { C:(102/470) } \\
0.55 / 4.48 \mathrm{E}-02 \\
\text { Gender } \\
\text { Males } \\
\text { C:(95/426) } \\
0.57 / 1.95 \mathrm{E}-02 \\
\text { Gender/Dx } \\
\text { M-MDD } \\
\text { C:(26/67) } \\
0.66 / 1.58 \mathrm{E}-02 \\
\text { M-PSYCHOSIS } \\
\text { C:(33/198) } \\
0.6 / 3.63 \mathrm{E}-02\end{array}$ & $\begin{array}{l}\text { Gender/Dx } \\
\text { M-BP } \\
\text { L:(34/91) } \\
1.65 / 2.20 \mathrm{E}-02\end{array}$ & $\begin{array}{l}\text { ADHD } \\
\text { Aggression } \\
\text { Alcohol } \\
\text { Anxiety } \\
\text { BP } \\
\text { Chronic stress } \\
\text { MDD } \\
\text { OCD } \\
\text { Panic disorder } \\
\text { Psychosis } \\
\text { PTSD } \\
\text { Suicide SZ }\end{array}$ & $\begin{array}{l}\text { Clozapine } \\
\text { Morphine } \\
\text { Mood stabilizers }\end{array}$ & 24 \\
\hline
\end{tabular}


Table 2 (continued)

\begin{tabular}{|c|c|c|c|c|c|c|c|c|c|c|}
\hline $\begin{array}{l}\text { Gene symbol/gene } \\
\text { name }\end{array}$ & Probesets & $\begin{array}{l}\text { Step 1 } \\
\text { Discovery } \\
\text { in blood } \\
\text { (direction } \\
\text { of change) } \\
\text { Method/ } \\
\text { score/\% } \\
\text { Up to } 6 \text { pts }\end{array}$ & $\begin{array}{l}\text { Step 2 } \\
\text { External } \\
\text { convergent } \\
\text { functional } \\
\text { genomics } \\
\text { (CFG) } \\
\text { Evidence for } \\
\text { involvement } \\
\text { in pain score } \\
\text { Up to } 12 \text { pts }\end{array}$ & $\begin{array}{l}\text { Step } 3 \\
\text { Validation } \\
\text { in blood } \\
\text { ANOVA } \\
p \text {-value/ } \\
\text { score Up } \\
\text { to } 6 \text { pts }\end{array}$ & $\begin{array}{l}\text { Step } 4 \\
\text { Best significant } \\
\text { prediction of } \\
\text { State-High Pain } \\
\text { (Cases/Total) } \\
\text { ROC AUC/ } \\
p \text {-value } \\
8 \text { pts All } \\
6 \text { pts Gender } \\
4 \text { pts Gender/Dx }\end{array}$ & $\begin{array}{l}\text { Step } 4 \\
\text { Best Significant } \\
\text { prediction of } \\
\text { Trait-Future ED } \\
\text { visits for Pain in } \\
\text { the first year } \\
\text { (Cases/Total) } \\
\text { ROC AUC/ } \\
\text { p-value } \\
8 \text { pts All } \\
6 \text { pts Gender } \\
4 \text { pts Gender/Dx }\end{array}$ & $\begin{array}{l}\text { Step } 4 \\
\text { Best significant predictions } \\
\text { of Trait- Future ED visits for } \\
\text { Pain in all future years } \\
\text { (Cases/Total) } \\
\text { OR/OR } p \text {-value } \\
8 \text { pts All } \\
6 \text { pts Gender } \\
4 \text { pts Gender/Dx }\end{array}$ & $\begin{array}{l}\text { Step } 5 \\
\text { Other psychiatric } \\
\text { and related } \\
\text { disorders evidence }\end{array}$ & $\begin{array}{l}\text { Step } 6 \\
\text { Drugs That } \\
\text { Modulate the } \\
\text { Biomarker in } \\
\text { opposite } \\
\text { Direction to } \\
\text { Pain }\end{array}$ & $\begin{array}{l}\text { CFE } \\
\text { Polyevidence } \\
\text { score for } \\
\text { involvement in } \\
\text { pain (based on } \\
\text { steps 1-4) }\end{array}$ \\
\hline $\begin{array}{l}\text { RAB33A } \\
\text { RAB33A, member } \\
\text { RAS oncogene } \\
\text { family }\end{array}$ & 206039_at & $\begin{array}{l}\text { (I) } \\
\mathrm{DE} / 6 \text { 90\% }\end{array}$ & 0 & NS & $\begin{array}{l}\text { Gender/Dx } \\
\text { F-MDD } \\
\text { C:(2/18) } \\
1 / 1.23 \mathrm{E}-02\end{array}$ & $\begin{array}{l}\text { Gender } \\
\text { Males } \\
\text { C:(95/426) } \\
0.56 / 3.60 \mathrm{E}-02\end{array}$ & $\begin{array}{l}\text { All } \\
\text { C:(239/501) } \\
1.14 / 2.21 \mathrm{E}-02 \\
\text { Gender } \\
\text { Males } \\
\text { C:(226/454) } \\
\text { 1.16/1.01E-02 } \\
\text { Gender/Dx } \\
\text { M-BP } \\
\text { L:(34/91) } \\
1.65 / 1.69 \mathrm{E}-03 \\
\text { M-MDD } \\
\text { C:(42/72) } \\
1.95 / 6.59 \mathrm{E}-04 \\
\text { L:(25/43) } \\
1.85 / 1.72 \mathrm{E}-02\end{array}$ & $\begin{array}{l}\text { Alcohol } \\
\text { Stress } \\
\text { MDD }\end{array}$ & & 24 \\
\hline $\begin{array}{l}Z Y X \\
\text { Zyxin }\end{array}$ & 238016_s_at & $\begin{array}{l}\text { (D) } \\
\mathrm{DE} / 457 \%\end{array}$ & 4 & NS & $\begin{array}{l}\text { Gender/Dx } \\
\text { F-BP } \\
\text { C:(4/21) } \\
0.78 / 4.44 \mathrm{E}-02\end{array}$ & $\begin{array}{l}\text { All } \\
\text { C:(102/470) } \\
0.55 / 4.80 \mathrm{E}-02 \\
\text { Gender } \\
\text { Males } \\
\text { C:(95/426) } \\
0.57 / 1.58 \mathrm{E}-02 \\
\text { Gender/Dx } \\
\text { M-PSYCHOSIS } \\
\text { C:(33/198) } \\
0.62 / 1.43 \mathrm{E}-02 \\
\text { M-SZA } \\
\text { C:(23/97) } \\
0.66 / 1.15 \mathrm{E}-02 \\
\text { M-BP } \\
\text { L:(9/80) } \\
0.71 / 2.26 \mathrm{E}-02\end{array}$ & $\begin{array}{l}\text { Gender/Dx } \\
\text { M-BP } \\
\text { L:(34/91) } \\
\text { 1.85/1.67E-02 } \\
\text { M-PTSD } \\
\text { C:(26/31) } \\
1.57 / 4.40 \mathrm{E}-02 \\
\text { L:(18/20) } \\
2.2 / 1.53 \mathrm{E}-02\end{array}$ & MDD & Clozapine & 24 \\
\hline $\begin{array}{l}\text { (Hs.696420) } \\
\text { MTERFI } \\
\text { Mitochondrial } \\
\text { transcription } \\
\text { termination factor } 1\end{array}$ & 243125_x_at & $\begin{array}{l}\text { (D) } \\
\mathrm{DE} / 6 \\
100 \%\end{array}$ & 0 & NS & $\begin{array}{l}\text { Gender/Dx } \\
\text { M-PSYCHOSIS } \\
\text { C:(19/96) } \\
0.67 / 1.01 \mathrm{E}-02 \\
\text { M-SZ } \\
\text { C:(11/64) } \\
0.77 / 2.27 \mathrm{E}-03 \\
\text { L:(7/39) } \\
0.71 / 3.95 \mathrm{E}-02\end{array}$ & $\begin{array}{l}\text { Gender/Dx } \\
\text { F-PTSD } \\
\text { C:(2/8) } \\
1 / 2.28 \mathrm{E}-02\end{array}$ & $\begin{array}{l}\text { All } \\
\text { C:(239/501) } \\
1.19 / 1.19 \mathrm{E}-02 \\
\text { L:(145/309) } \\
1.2 / 4.81 \mathrm{E}-02 \\
\text { Gender } \\
\text { Males } \\
\text { C:(226/454) } \\
\text { 1.19/1.51E-02 } \\
\text { Gender/Dx } \\
\text { M-PSYCHOSIS } \\
\text { C:(95/201) } \\
\text { 1.41/8.86E-03 } \\
\text { M-SZ } \\
\text { C:(42/103) } \\
\text { 1.4/4.47E-02 } \\
\text { M-SZA } \\
\text { C:(53/98) } \\
\text { 1.44/4.72E-02 }\end{array}$ & $\begin{array}{l}\text { PTSD } \\
\text { Suicide }\end{array}$ & & 22 \\
\hline $\begin{array}{l}\text { COL27A1 } \\
\text { Collagen type } \\
\text { XXVII alpha } 1 \\
\text { chain }\end{array}$ & 225293_at & $\begin{array}{l}\text { (D) } \\
\mathrm{DE} / 479 \%\end{array}$ & 4 & $\begin{array}{l}\text { 7.47E-01/2 } \\
\text { Stepwise }\end{array}$ & $\begin{array}{l}\text { Gender/Dx } \\
\text { M-MDD } \\
\text { L:(13/43) } \\
0.66 / 4.79 E-02\end{array}$ & $\begin{array}{l}\text { Gender/Dx } \\
\text { M-MDD } \\
\text { C:(26/67) } \\
0.63 / 3.38 \mathrm{E}-02 \\
\text { M-PSYCHOSIS } \\
\text { C:(33/198) } \\
0.61 / 2.79 \mathrm{E}-02 \\
\text { M-SZA } \\
\text { C:(23/97) } \\
0.68 / 4.96 \mathrm{E}-03 \\
\text { L:(13/55) } 0.7 / \\
1.62 \mathrm{E}-02\end{array}$ & $\begin{array}{l}\text { Gender/Dx } \\
\text { M-PTSD } \\
\text { L:(18/20) } \\
1.96 / 2.37 \mathrm{E}-02\end{array}$ & Tourette syndrome & Lithium & 22 \\
\hline $\begin{array}{l}\text { HRAS } \\
\text { HRas proto- } \\
\text { oncogene, GTPase }\end{array}$ & 212983_at & $\begin{array}{l}\text { (I) } \\
\mathrm{DE} / 697 \%\end{array}$ & 0 & NS & $\begin{array}{l}\text { All } \\
\text { C:(101/411) } \\
0.56 / 3.47 \mathrm{E}-02 \\
\text { L:(61/248) } \\
0.58 / 3.01 \mathrm{E}-02 \\
\text { Gender } \\
\text { Male } \\
\text { C:(85/346) } \\
0.57 / 2.72 \mathrm{E}-02 \\
\text { L:(51/212) } \\
0.61 / 1.18 \mathrm{E}-02 \\
\text { Gender/Dx } \\
\text { M-SZ } \\
\text { C:(11/64) } \\
0.68 / 2.79 \mathrm{E}-02 \\
\text { M-MDD }\end{array}$ & $\begin{array}{l}\text { Gender/Dx } \\
\text { F-PTSD } \\
\text { C:(2/8) } \\
1 / 2.28 \mathrm{E}-02\end{array}$ & $\begin{array}{l}\text { Gender/Dx } \\
\text { M-MDD } \\
\text { C:(42/72) } \\
2.2 / 3.38 \mathrm{E}-06^{\mathrm{a}} \\
\text { L:(25/43) } \\
2.25 / \mathbf{2 . 6 1 E - 0 4} \mathbf{- 1}^{\mathrm{a}}\end{array}$ & $\begin{array}{l}\text { Alcohol } \\
\text { BP } \\
\text { Longevity suicide } \\
\text { SZ }\end{array}$ & ISIS 2503 & 22 \\
\hline
\end{tabular}


Table 2 (continued)

\begin{tabular}{|c|c|c|c|c|c|c|c|c|c|c|}
\hline $\begin{array}{l}\text { Gene symbol/gene } \\
\text { name }\end{array}$ & Probesets & $\begin{array}{l}\text { Step } 1 \\
\text { Discovery } \\
\text { in blood } \\
\text { (direction } \\
\text { of change) } \\
\text { Method/ } \\
\text { score } \% \\
\text { Up to } 6 \text { pts }\end{array}$ & $\begin{array}{l}\text { Step } 2 \\
\text { External } \\
\text { convergent } \\
\text { functional } \\
\text { genomics } \\
\text { (CFG) } \\
\text { Evidence for } \\
\text { involvement } \\
\text { in pain score } \\
\text { Up to } 12 \text { pts }\end{array}$ & $\begin{array}{l}\text { Step } 3 \\
\text { Validation } \\
\text { in blood } \\
\text { ANOVA } \\
p \text {-value/ } \\
\text { score Up } \\
\text { to } 6 \text { pts }\end{array}$ & $\begin{array}{l}\text { Step } 4 \\
\text { Best significant } \\
\text { prediction of } \\
\text { State-High Pain } \\
\text { (Cases/Total) } \\
\text { ROC AUC/ } \\
\text { p-value } \\
8 \text { pts All } \\
6 \text { pts Gender } \\
4 \text { pts Gender/Dx }\end{array}$ & $\begin{array}{l}\text { Step } 4 \\
\text { Best Significant } \\
\text { prediction of } \\
\text { Trait-Future ED } \\
\text { visits for Pain in } \\
\text { the first year } \\
\text { (Cases/Total) } \\
\text { ROC AUC/ } \\
p \text {-value } \\
8 \text { pts All } \\
6 \text { pts Gender } \\
4 \text { pts Gender/Dx }\end{array}$ & $\begin{array}{l}\text { Step } 4 \\
\text { Best significant predictions } \\
\text { of Trait- Future ED visits for } \\
\text { Pain in all future years } \\
\text { (Cases/Total) } \\
\text { OR/OR } p \text {-value } \\
8 \text { pts All } \\
6 \text { pts Gender } \\
4 \text { pts Gender/Dx }\end{array}$ & $\begin{array}{l}\text { Step } 5 \\
\text { Other psychiatric } \\
\text { and related } \\
\text { disorders evidence }\end{array}$ & $\begin{array}{l}\text { Step } 6 \\
\text { Drugs That } \\
\text { Modulate the } \\
\text { Biomarker in } \\
\text { opposite } \\
\text { Direction to } \\
\text { Pain }\end{array}$ & $\begin{array}{l}\text { CFE } \\
\text { Polyevidence } \\
\text { score for } \\
\text { involvement in } \\
\text { pain (based on } \\
\text { steps 1-4) }\end{array}$ \\
\hline $\begin{array}{l}C A L C A \\
\text { Calcitonin related } \\
\text { polypeptide alpha }\end{array}$ & 210727_at & $\begin{array}{l}\text { (D) } \\
\mathrm{DE} / 454 \%\end{array}$ & 7 & NS & $\begin{array}{l}\text { L:(13/43) } \\
0.71 / 1.61 \mathrm{E}-02 \\
\text { Gender } \\
\text { Females } \\
\text { C:(16/63) } \\
0.66 / 3.12 \mathrm{E}-02 \\
\text { Gender/Dx } \\
\text { F-MDD } \\
\text { C:(2/18) } \\
0.97 / 1.75 \mathrm{E}-02 \\
\text { F-BP } \\
\text { L:(3/11) } \\
0.88 / 3.31 \mathrm{E}-02 \\
\text { M-MDD } \\
\text { L:(13/43) } \\
0.66 / 4.79 \mathrm{E}-02\end{array}$ & $\begin{array}{l}\text { Gender/Dx } \\
\text { F-PTSD } \\
\text { C:(2/8) } \\
1 / 2.28 \mathrm{E}-02 \\
\text { Gender/Dx } \\
\text { M-PSYCHOSIS } \\
\text { C:(33/198) } \\
0.6 / 3.87 \mathrm{E}-02\end{array}$ & & $\begin{array}{l}\text { Alcohol } \\
\text { Anxiety } \\
\text { Panic disorder }\end{array}$ & $\begin{array}{l}\text { Omega-3 fatty } \\
\text { acids } \\
\text { Lithium }\end{array}$ & 21 \\
\hline $\begin{array}{l}(\text { Hs.596713) } \\
\text { PPPIR14B } \\
\text { Protein phosphatase } \\
1 \text { regulatory } \\
\text { inhibitor subunit } \\
\text { 14B }\end{array}$ & 226138_s_at & $\begin{array}{l}\text { (D) } \\
\mathrm{DE} / 690 \%\end{array}$ & 0 & $\begin{array}{l}6.28 \mathrm{E}-02 / 2 \\
\text { Stepwise }\end{array}$ & $\begin{array}{l}\text { Gender/Dx } \\
\text { F-BP } \\
\text { C:(4/21) } \\
0.94 / 3.61 \mathrm{E}-03 \\
\text { L:(3/11) } \\
0.92 / 2.06 \mathrm{E}-02 \\
\text { M-MDD } \\
\text { L:(13/43) } \\
0.73 / 9.98 \mathrm{E}-03\end{array}$ & & $\begin{array}{l}\text { All } \\
\text { C:(239/501) } \\
1.15 / 1.43 \mathrm{E}-02 \\
\text { Gender } \\
\text { Males } \\
\text { C:(226/454) } \\
1.19 / 4.84 \mathrm{E}-03 \\
\text { L:(138/282) } \\
1.2 / 3.94 \mathrm{E}-02 \\
\text { Gender/Dx } \\
\text { M-PSYCHOSIS } \\
\text { C:(95/201) } \\
1.35 / 3.06 \mathrm{E}-03 \\
\text { M-SZ } \\
\text { C:(42/103) } \\
1.53 / 3.19 \mathrm{E}-02 \\
\text { M-SZA } \\
\text { C:(53/98) } \\
1.41 / 9.26 \mathrm{E}-03\end{array}$ & SZ & Lithium & 20 \\
\hline $\begin{array}{l}\text { ASTN2 } \\
\text { Astrotactin } 2\end{array}$ & 1554816_at & $\begin{array}{l}\text { (I) } \\
\mathrm{DE} / 683 \%\end{array}$ & 2 & $\begin{array}{l}1.71 \mathrm{E}-01 \\
/ 2 \\
\text { Stepwise }\end{array}$ & & $\begin{array}{l}\text { Gender/Dx } \\
\text { F-MDD } \\
\text { L:(2/6) } \\
1 / 3.20 \mathrm{E}-02\end{array}$ & $\begin{array}{l}\text { Gender } \\
\text { Female } \\
\text { L:(7/27) } \\
2.45 / 4.36 \mathrm{E}-02\end{array}$ & $\begin{array}{l}\text { Suicide } \\
\text { SZ } \\
\text { ASD } \\
\text { BP } \\
\text { MDD }\end{array}$ & Antipsychotics & 20 \\
\hline $\begin{array}{l}\text { ELAC2 } \\
\text { ElaC ribonuclease } \\
\mathrm{Z} 2\end{array}$ & 201766_at & $\begin{array}{l}\text { (D) } \\
\mathrm{DE} / 452 \%\end{array}$ & 2 & $\begin{array}{l}\text { 4.11E-02/4 } \\
\text { Nominal }\end{array}$ & $\begin{array}{l}\text { Gender/Dx } \\
\text { M-MDD } \\
\text { L:(13/43) } \\
0.73 / 8.66 \mathrm{E}-03\end{array}$ & & $\begin{array}{l}\text { Gender } \\
\text { Males } \\
\text { L:(138/282) } \\
\text { 1.2/4.61E-02 } \\
\text { Gender/Dx } \\
\text { M-BP } \\
\text { L:(34/91) } \\
\text { 1.55/4.79E-02 } \\
\text { M-MDD } \\
\text { C:(42/72) } \\
\text { 1.69/2.47E-03 } \\
\text { L:(25/43) } \\
\text { 1.85/3.66E-02 }\end{array}$ & ASD & & 20 \\
\hline $\begin{array}{l}H L A-D Q B I \\
\text { Major } \\
\text { histocompatibility } \\
\text { complex, class II, } \\
\text { DQ beta 1 }\end{array}$ & 212998_x_at & $\begin{array}{l}\text { (I) } \\
\mathrm{DE} / 451 \%\end{array}$ & 8 & NS & $\begin{array}{l}\text { Gender/Dx } \\
\text { M-SZ } \\
\text { C:(11/64) } \\
0.68 / 3.41 \mathrm{E}-02 \\
\text { F-MDD } \\
\text { C:(2/18) } \\
\text { 1/1.23E-02 } \\
\text { M-MDD } \\
\text { L:(13/43) } \\
0.67 / 4.28 \mathrm{E}-02\end{array}$ & & $\begin{array}{l}\text { Gender/Dx } \\
\text { M-BP } \\
\text { L:(34/91) } \\
1.63 / 1.30 \mathrm{E}-02\end{array}$ & $\begin{array}{l}\text { Alcohol } \\
\text { Depression } \\
\text { Longevity stress } \\
\text { Suicide } \\
\text { SZ }\end{array}$ & Antipsychotics & 20 \\
\hline $\begin{array}{l}\text { HLA-DQBI } \\
\text { Major } \\
\text { histocompatibility } \\
\text { complex, class II, } \\
\text { DQ beta 1 }\end{array}$ & 211656_x_at & $\begin{array}{l}\text { (I) } \\
\mathrm{DE} / 459 \%\end{array}$ & 8 & NS & $\begin{array}{l}\text { Gender/Dx } \\
\text { F-MDD } \\
\text { C:(2/18) } \\
\text { 1/1.23E-02 } \\
\text { M-SZ } \\
\text { C:(11/64) } \\
0.68 / 3.15 \mathrm{E}-02 \\
\text { M-SZ } \\
\text { C:(11/64) } \\
0.74 / 5.90 \mathrm{E}-03 \\
\text { L:(7/39) } \\
0.72 / 3.36 \mathrm{E}-02 \\
\text { M-MDD } \\
\text { L:(13/43) } \\
0.69 / 2.68 \mathrm{E}-02 \\
\text { M-PSYCHOSIS } \\
\text { L:(10/56) } \\
0.69 / 3.29 \mathrm{E}-02\end{array}$ & $\begin{array}{l}\text { Gender/Dx } \\
\text { M-MDD } \\
\text { C:(26/67) } \\
0.62 / 4.85 E-02\end{array}$ & & $\begin{array}{l}\text { Alcohol } \\
\text { BP } \\
\text { Depression } \\
\text { Longevity } \\
\text { PTSD } \\
\text { Stress } \\
\text { Suicide } \\
\text { SZ }\end{array}$ & Antipsychotics & 20 \\
\hline
\end{tabular}


Table 2 (continued)

\begin{tabular}{|c|c|c|c|c|c|c|c|c|c|c|}
\hline $\begin{array}{l}\text { Gene symbol/gene } \\
\text { name }\end{array}$ & Probesets & $\begin{array}{l}\text { Step 1 } \\
\text { Discovery } \\
\text { in blood } \\
\text { (direction } \\
\text { of change) } \\
\text { Method/ } \\
\text { score/\% } \\
\text { Up to } 6 \text { pts }\end{array}$ & $\begin{array}{l}\text { Step } 2 \\
\text { External } \\
\text { convergent } \\
\text { functional } \\
\text { genomics } \\
\text { (CFG) } \\
\text { Evidence for } \\
\text { involvement } \\
\text { in pain score } \\
\text { Up to } 12 \text { pts }\end{array}$ & $\begin{array}{l}\text { Step } 3 \\
\text { Validation } \\
\text { in blood } \\
\text { ANOVA } \\
p \text {-value/ } \\
\text { score Up } \\
\text { to } 6 \text { pts }\end{array}$ & $\begin{array}{l}\text { Step } 4 \\
\text { Best significant } \\
\text { prediction of } \\
\text { State-High Pain } \\
\text { (Cases/Total) } \\
\text { ROC AUC/ } \\
\text { p-value } \\
8 \text { pts All } \\
6 \text { pts Gender } \\
4 \text { pts Gender/Dx }\end{array}$ & $\begin{array}{l}\text { Step } 4 \\
\text { Best Significant } \\
\text { prediction of } \\
\text { Trait-Future ED } \\
\text { visits for Pain in } \\
\text { the first year } \\
\text { (Cases/Total) } \\
\text { ROC AUC/ } \\
\text { p-value } \\
8 \text { pts All } \\
6 \text { pts Gender } \\
4 \text { pts Gender/Dx }\end{array}$ & $\begin{array}{l}\text { Step } 4 \\
\text { Best significant predictions } \\
\text { of Trait- Future ED visits for } \\
\text { Pain in all future years } \\
\text { (Cases/Total) } \\
\text { OR/OR p-value } \\
8 \text { pts All } \\
6 \text { pts Gender } \\
4 \text { pts Gender/Dx }\end{array}$ & $\begin{array}{l}\text { Step } 5 \\
\text { Other psychiatric } \\
\text { and related } \\
\text { disorders evidence }\end{array}$ & $\begin{array}{l}\text { Step } 6 \\
\text { Drugs That } \\
\text { Modulate the } \\
\text { Biomarker in } \\
\text { opposite } \\
\text { Direction to } \\
\text { Pain }\end{array}$ & $\begin{array}{l}\text { CFE } \\
\text { Polyevidence } \\
\text { score for } \\
\text { involvement in } \\
\text { pain (based on } \\
\text { steps 1-4) }\end{array}$ \\
\hline $\begin{array}{l}\text { PNOC } \\
\text { Prepronociceptin }\end{array}$ & 205901_at & $\begin{array}{l}\text { (I) } \\
\mathrm{DE} / 462 \%\end{array}$ & 4 & NS & $\begin{array}{l}\text { Gender/Dx } \\
\text { M-SZ } \\
\text { L:(7/39) } \\
0.72 / 3.36 \mathrm{E}-02\end{array}$ & $\begin{array}{l}\text { Gender/Dx } \\
\text { M-BP } \\
\text { L:(9/80) } \\
0.68 / 4.20 \mathrm{E}-02\end{array}$ & $\begin{array}{l}\text { Gender/Dx } \\
\text { M-BP } \\
\text { C:(53/134) } \\
1.23 / 4.73 \mathrm{E}-02 \\
\text { L:(34/91) } \\
\text { 1.26/2.67E-02 } \\
\text { M-MDD } \\
\text { C:(42/72) } \\
\text { 1.4/2.09E-02 }\end{array}$ & $\begin{array}{l}\text { Addictions } \\
\text { BP } \\
\text { MDD } \\
\text { SZ } \\
\text { Stress }\end{array}$ & & 20 \\
\hline $\begin{array}{l}\text { TCF15 } \\
\text { Transcription factor } \\
15 \text { (Basic helix- } \\
\text { loop-helix) }\end{array}$ & 207306_at & $\begin{array}{l}\text { (D) } \\
\mathrm{DE} / 694 \%\end{array}$ & 2 & NS & $\begin{array}{l}\text { Gender/Dx } \\
\text { F-MDD } \\
\text { C:(2/18) } \\
0.94 / 2.46 \mathrm{E}-02 \\
\text { M-MDD } \\
\text { L:(13/43) } \\
0.68 / 3.21 \mathrm{E}-02\end{array}$ & & $\begin{array}{l}\text { All } \\
\text { C:(239/501) } \\
\text { 1.11/4.85E-02 } \\
\text { Gender } \\
\text { Males } \\
\text { C:(226/454) } \\
\text { 1.14/2.39E-02 } \\
\text { Gender/Dx } \\
\text { M-BP } \\
\text { L:(34/91) } \\
\text { 2.22/2.61E-03 }\end{array}$ & $\begin{array}{l}\text { Universal suicide } \\
\text { Male suicide }\end{array}$ & & 20 \\
\hline $\begin{array}{l}\text { TOP3A } \\
\text { Topoisomerase } \\
\text { (DNA) III alpha }\end{array}$ & 214300_s_at & $\begin{array}{l}\text { (D) } \\
\mathrm{DE} / 451 \%\end{array}$ & 4 & NS & $\begin{array}{l}\text { Gender/Dx } \\
\text { F-BP } \\
\text { C:(4/21) } \\
0.84 / 1.97 \mathrm{E}-02\end{array}$ & & $\begin{array}{l}\text { All } \\
\text { L:(145/309) } 1.18 / 4.66 \mathrm{E}-02 \\
\text { Gender } \\
\text { Males } \\
\text { L:(138/282) } \\
1.2 / 3.88 \mathrm{E}-02 \\
\text { Gender/Dx } \\
\text { M-SZ } \\
\text { L:(25/64) } \\
1.75 / 4.72 \mathrm{E}-02\end{array}$ & & $\begin{array}{l}\text { Omega-3 fatty } \\
\text { acids }\end{array}$ & 20 \\
\hline $\begin{array}{l}(\mathrm{H} 05785) \\
L R R C 75 \mathrm{~A} \\
\text { Leucine rich repeat } \\
\text { containing } 75 \mathrm{~A}\end{array}$ & 236913_at & $\begin{array}{l}\text { (D) } \\
\mathrm{AP} / 6 \text { 97\% }\end{array}$ & 0 & NS & $\begin{array}{l}\text { Gender/Dx } \\
\text { F-MDD } \\
\text { C:(2/18) } \\
0.94 / 2.46 \mathrm{E}-02\end{array}$ & $\begin{array}{l}\text { All } \\
\text { C:(102/470) } \\
0.56 / 2.27 \mathrm{E}-02 \\
\text { L:(58/287) } \\
0.58 / 3.38 \mathrm{E}-02 \\
\text { Gender } \\
\text { Males } \\
\text { C:(95/426) } \\
0.57 / 1.64 \mathrm{E}-02 \\
\text { L:(54/261) } \\
0.59 / 2.71 \mathrm{E}-02 \\
\text { Gender/Dx } \\
\text { F-PTSD } \\
\text { C:(2/8) } \\
\text { 1/2.28E-02 } \\
\text { M-PSYCHOSIS } \\
\text { C:(33/198) } \\
0.65 / 3.29 \mathrm{E}-03 \\
\text { M-SZA } \\
\text { C:(23/97) } \\
0.68 / 5.21 \mathrm{E}-03 \\
\text { M-SZA } \\
\text { L:(13/55) } \\
0.66 / 4.42 \mathrm{E}-02 \\
\text { M-MDD } \\
\text { L:(16/39) } \\
\text { 0.76/3.64E-03 }\end{array}$ & & $\begin{array}{l}\text { Alcohol } \\
\text { BP } \\
\text { Suicide } \\
\text { SZ }\end{array}$ & Clozapine & 18 \\
\hline $\begin{array}{l}C L S P N \\
\text { Claspin }\end{array}$ & 242150_at & $\begin{array}{l}\text { (I) } \\
\mathrm{AP} / 695 \%\end{array}$ & 0 & NS & $\begin{array}{l}\text { Gender/Dx } \\
\text { M-PSYCHOSIS } \\
\text { C:(19/96) } \\
0.65 / 2.48 \mathrm{E}-02\end{array}$ & $\begin{array}{l}\text { All } \\
\text { L:(58/287) } \\
0.57 / 4.62 \mathrm{E}-02 \\
\text { Gender/Dx } \\
\text { F-MDD } \\
\text { L:(2/6) } \\
1 / 3.20 \mathrm{E}-02 \\
\text { M-MDD } \\
\text { L:(16/39) } \\
0.67 / 4.08 \mathrm{E}-02\end{array}$ & & Suicide & & 18 \\
\hline $\begin{array}{l}\text { COL2AI } \\
\text { Collagen type II } \\
\text { alpha } 1 \text { chain }\end{array}$ & 217404_s_at & $\begin{array}{l}\text { (D) } \\
\mathrm{DE} / 454 \%\end{array}$ & 4 & NS & & $\begin{array}{l}\text { Gender } \\
\text { Males } \\
\text { C:(95/426) } \\
0.56 / 3.53 \mathrm{E}-02 \\
\text { Gender/Dx } \\
\text { M-PSYCHOSIS } \\
\text { C:(33/198) } \\
0.63 / 7.32 \mathrm{E}-03 \\
\text { M-SZA } \\
\text { C:(23/97) } \\
0.66 / 1.08 \mathrm{E}-02 \\
\text { L:(13/55) } \\
0.66 / 3.73 \mathrm{E}-02\end{array}$ & $\begin{array}{l}\text { Gender/Dx } \\
\text { M-PTSD } \\
\text { C:(26/31) } \\
1.83 / 4.38 \mathrm{E}-03 \\
\text { L:(18/20) } \\
2.3 / 1.08 \mathrm{E}-02\end{array}$ & Aging & & 18 \\
\hline
\end{tabular}


Table 2 (continued)

\begin{tabular}{|c|c|c|c|c|c|c|c|c|c|c|}
\hline $\begin{array}{l}\text { Gene symbol/gene } \\
\text { name }\end{array}$ & Probesets & $\begin{array}{l}\text { Step } 1 \\
\text { Discovery } \\
\text { in blood } \\
\text { (direction } \\
\text { of change) } \\
\text { Method/ } \\
\text { score/\% } \\
\text { Up to } 6 \text { pts }\end{array}$ & $\begin{array}{l}\text { Step } 2 \\
\text { External } \\
\text { convergent } \\
\text { functional } \\
\text { genomics } \\
\text { (CFG) } \\
\text { Evidence for } \\
\text { involvement } \\
\text { in pain score } \\
\text { Up to } 12 \text { pts }\end{array}$ & $\begin{array}{l}\text { Step } 3 \\
\text { Validation } \\
\text { in blood } \\
\text { ANOVA } \\
p \text {-value/ } \\
\text { score Up } \\
\text { to } 6 \text { pts }\end{array}$ & $\begin{array}{l}\text { Step } 4 \\
\text { Best significant } \\
\text { prediction of } \\
\text { State-High Pain } \\
\text { (Cases/Total) } \\
\text { ROC AUC/ } \\
\text { p-value } \\
8 \text { pts All } \\
6 \text { pts Gender } \\
4 \text { pts Gender/Dx }\end{array}$ & $\begin{array}{l}\text { Step } 4 \\
\text { Best Significant } \\
\text { prediction of } \\
\text { Trait-Future ED } \\
\text { visits for Pain in } \\
\text { the first year } \\
\text { (Cases/Total) } \\
\text { ROC AUC/ } \\
p \text {-value } \\
8 \text { pts All } \\
6 \text { pts Gender } \\
4 \text { pts Gender/Dx }\end{array}$ & $\begin{array}{l}\text { Step } 4 \\
\text { Best significant predictions } \\
\text { of Trait- Future ED visits for } \\
\text { Pain in all future years } \\
\text { (Cases/Total) } \\
\text { OR/OR } p \text {-value } \\
8 \text { pts All } \\
6 \text { pts Gender } \\
4 \text { pts Gender/Dx }\end{array}$ & $\begin{array}{l}\text { Step } 5 \\
\text { Other psychiatric } \\
\text { and related } \\
\text { disorders evidence }\end{array}$ & $\begin{array}{l}\text { Step } 6 \\
\text { Drugs That } \\
\text { Modulate the } \\
\text { Biomarker in } \\
\text { opposite } \\
\text { Direction to } \\
\text { Pain }\end{array}$ & $\begin{array}{l}\text { CFE } \\
\text { Polyevidence } \\
\text { score for } \\
\text { involvement in } \\
\text { pain (based on } \\
\text { steps 1-4) }\end{array}$ \\
\hline $\begin{array}{l}H L A-D Q B I \\
\text { Major } \\
\text { histocompatibility } \\
\text { complex, class II, } \\
\text { DQ beta 1 }\end{array}$ & 210747_at & $\begin{array}{l}\text { (D) } \\
\mathrm{DE} / 244 \%\end{array}$ & 8 & NS & & & $\begin{array}{l}\text { All } \\
\text { C:(239/501) } \\
\text { 1.17/1.03E-02 } \\
\text { Gender } \\
\text { Males } \\
\text { C:(226/454) } \\
\text { 1.19/6.06E-03 } \\
\text { Gender/Dx } \\
\text { M-MDD } \\
\text { C:(42/72) } \\
\text { 1.35/3.68E-02 } \\
\text { M-PSYCHOSIS } \\
\text { C:(95/201) } \\
\text { 1.26/1.33E-02 } \\
\text { M-SZA } \\
\text { C:(53/98) } \\
1.33 / 2.06 \mathrm{E}-02\end{array}$ & $\begin{array}{l}\text { Addiction } \\
\text { Stress }\end{array}$ & Benzodiazepines & 18 \\
\hline Hs. 554262 & 210703_at & $\begin{array}{l}\text { (I) } \\
\mathrm{AP} / 6 \\
100 \%\end{array}$ & 0 & NS & & $\begin{array}{l}\text { All } \\
\text { C:(102/470) } \\
0.56 / 2.38 \mathrm{E}-02 \\
\text { L:(58/287) } \\
0.58 / 2.49 \mathrm{E}-02 \\
\text { Gender } \\
\text { Males } \\
\text { C:(95/426) } \\
0.56 / 4.18 \mathrm{E}-02 \\
\text { L:(54/261) } \\
0.59 / 1.65 \mathrm{E}-02 \\
\text { Gender/Dx } \\
\text { F-MDD } \\
\text { C:(4/11) } \\
0.82 / 4.45 \mathrm{E}-02 \\
\text { M-BP } \\
\text { C:(18/120) } \\
0.67 / 1.08 \mathrm{E}-02 \\
\text { M-MDD } \\
\text { L:(16/39) } \\
0.67 / 4.08 \mathrm{E}-02\end{array}$ & $\begin{array}{l}\text { Gender/Dx } \\
\text { F-MDD } \\
\text { C:(4/12) } \\
\text { 7/4.47E-02 } \\
\text { M-MDD } \\
\text { L:(25/43) } \\
\text { 2.13/7.30E-03 }\end{array}$ & Suicide & & 18 \\
\hline $\begin{array}{l}\text { PIK3CD } \\
\text { Phosphatidylinosi- } \\
\text { tol-4,5- } \\
\text { bisphosphate } 3- \\
\text { kinase catalytic } \\
\text { subunit delta }\end{array}$ & 211230_s_at & $\begin{array}{l}\text { (D) } \\
\mathrm{DE} / 683 \%\end{array}$ & 0 & $\begin{array}{l}1.59 E-02 / 4 \\
\text { Nominal }\end{array}$ & & & $\begin{array}{l}\text { All } \\
\text { C:(239/501) } \\
\text { 1.13/3.18E-02 } \\
\text { Gender } \\
\text { Males } \\
\text { C:(226/454) } \\
\text { 1.14/2.71E-02 } \\
\text { Gender/Dx } \\
\text { M-BP } \\
\text { C:(53/134) } \\
\text { 1.3/2.85E-02 } \\
\text { L:(34/91) } \\
1.57 / 2.01 \mathrm{E}-02 \\
\text { M-MDD } \\
\text { C:(42/72) } \\
\text { 1.65/5.12E-03 }\end{array}$ & $\begin{array}{l}\text { Alcohol } \\
\text { Chronic stress } \\
\text { Longevity } \\
\text { Suicide } \\
\text { SZ }\end{array}$ & $\begin{array}{l}\text { Clozapine } \\
\text { Lithium } \\
\text { Valproate }\end{array}$ & 18 \\
\hline $\begin{array}{l}\text { SVEPI } \\
\text { Sushi, von } \\
\text { willebrand factor } \\
\text { type A, EGF And } \\
\text { pentraxin domain } \\
\text { containing 1 }\end{array}$ & 236927_at & $\begin{array}{l}\text { (I) } \\
\mathrm{DE} / 249 \%\end{array}$ & 4 & $\begin{array}{l}2.17 E-02 / 4 \\
\text { Nominal }\end{array}$ & $\begin{array}{l}\text { Gender/Dx } \\
\text { F-PTSD } \\
\text { C:(5/12) } \\
0.8 / 4.41 \mathrm{E}-02 \\
\text { M-PTSD } \\
\text { C:(13/38) } \\
0.67 / 4.68 \mathrm{E}-02\end{array}$ & $\begin{array}{l}\text { Gender/Dx } \\
\text { F-MDD } \\
\text { C:(4/11) } \\
0.82 / 4.41 \mathrm{E}-02\end{array}$ & & $\begin{array}{l}\text { Addiction } \\
\text { SZ }\end{array}$ & $\begin{array}{l}\text { Omega-3 fatty } \\
\text { acids }\end{array}$ & 18 \\
\hline $\begin{array}{l}\text { TNFRSF11B } \\
\text { TNF receptor } \\
\text { superfamily } \\
\text { member 11b }\end{array}$ & 204932_at & $\begin{array}{l}\text { (D) } \\
\mathrm{DE} / 237 \%\end{array}$ & 4 & $\begin{array}{l}2.67 E-02 / 4 \\
\text { Nominal }\end{array}$ & $\begin{array}{l}\text { Gender/Dx } \\
\text { F-BP } \\
\text { C:(4/21) } \\
0.81 / 3.00 \mathrm{E}-02 \\
\text { M-MDD } \\
\text { L:(13/43) } \\
0.71 / 1.72 \mathrm{E}-02\end{array}$ & & $\begin{array}{l}\text { Gender/Dx } \\
\text { M-MDD } \\
\text { C:(42/72) } \\
1.42 / 4.25 \mathrm{E}-02 \\
\mathrm{~L}:(25 / 43) \\
1.59 / 3.84 \mathrm{E}-02\end{array}$ & $\begin{array}{l}\text { Stress } \\
\text { PTSD }\end{array}$ & & 18 \\
\hline $\begin{array}{l}\text { ZNF91 } \\
\text { zinc finger protein } \\
91\end{array}$ & 244259_s_at & $\begin{array}{l}\text { (I) } \\
\mathrm{AP} / 6 \text { 95\% }\end{array}$ & 0 & $\begin{array}{l}\text { 6.37E-01/2 } \\
\text { Stepwise }\end{array}$ & & $\begin{array}{l}\text { Gender/Dx } \\
\text { F-MDD } \\
\text { C:(4/11) } \\
0.93 / 1.17 \mathrm{E}-02\end{array}$ & $\begin{array}{l}\text { Gender } \\
\text { Females } \\
\text { C:(13/47) } \\
2.12 / 1.03 \mathrm{E}-02 \\
\text { Gender/Dx } \\
\text { F-BP } \\
\text { C:(2/16) } \\
4.21 / 4.55 \mathrm{E}-02 \\
\text { M-BP } \\
\text { C:(53/134) } \\
\text { 1.35/1.26E-02 }\end{array}$ & $\begin{array}{l}\text { Alcohol } \\
\text { Circadian } \\
\text { abnormalities } \\
\text { PTSD }\end{array}$ & & 18 \\
\hline
\end{tabular}


Table 2 (continued)

\begin{tabular}{|c|c|c|c|c|c|c|c|c|c|c|}
\hline $\begin{array}{l}\text { Gene symbol/gene } \\
\text { name }\end{array}$ & Probesets & $\begin{array}{l}\text { Step 1 } \\
\text { Discovery } \\
\text { in blood } \\
\text { (direction } \\
\text { of change) } \\
\text { Method/ } \\
\text { score/\% } \\
\text { Up to } 6 \text { pts }\end{array}$ & $\begin{array}{l}\text { Step } 2 \\
\text { External } \\
\text { convergent } \\
\text { functional } \\
\text { genomics } \\
\text { (CFG) } \\
\text { Evidence for } \\
\text { involvement } \\
\text { in pain score } \\
\text { Up to } 12 \text { pts }\end{array}$ & $\begin{array}{l}\text { Step } 3 \\
\text { Validation } \\
\text { in blood } \\
\text { ANOVA } \\
p \text {-value/ } \\
\text { score Up } \\
\text { to } 6 \text { pts }\end{array}$ & $\begin{array}{l}\text { Step } 4 \\
\text { Best significant } \\
\text { prediction of } \\
\text { State-High Pain } \\
\text { (Cases/Total) } \\
\text { ROC AUC/ } \\
\text { p-value } \\
8 \text { pts All } \\
6 \text { pts Gender } \\
4 \text { pts Gender/Dx }\end{array}$ & $\begin{array}{l}\text { Step } 4 \\
\text { Best Significant } \\
\text { prediction of } \\
\text { Trait-Future ED } \\
\text { visits for Pain in } \\
\text { the first year } \\
\text { (Cases/Total) } \\
\text { ROC AUC/ } \\
p \text {-value } \\
8 \text { pts All } \\
6 \text { pts Gender } \\
4 \text { pts Gender/Dx }\end{array}$ & $\begin{array}{l}\text { Step } 4 \\
\text { Best significant predictions } \\
\text { of Trait- Future ED visits for } \\
\text { Pain in all future years } \\
\text { (Cases/Total) } \\
\text { OR/OR } p \text {-value } \\
8 \text { pts All } \\
6 \text { pts Gender } \\
4 \text { pts Gender/Dx }\end{array}$ & $\begin{array}{l}\text { Step } 5 \\
\text { Other psychiatric } \\
\text { and related } \\
\text { disorders evidence }\end{array}$ & $\begin{array}{l}\text { Step 6 } \\
\text { Drugs That } \\
\text { Modulate the } \\
\text { Biomarker in } \\
\text { opposite } \\
\text { Direction to } \\
\text { Pain }\end{array}$ & $\begin{array}{l}\text { CFE } \\
\text { Polyevidence } \\
\text { score for } \\
\text { involvement in } \\
\text { pain (based on } \\
\text { steps 1-4) }\end{array}$ \\
\hline $\begin{array}{l}\text { CDK6 } \\
\text { Cyclin dependent } \\
\text { kinase } 6\end{array}$ & 224851_at & $\begin{array}{l}\text { (I) } \\
\mathrm{DE} / 456 \% \\
\text { (I) } \\
\mathrm{AP} / 242 \%\end{array}$ & 4 & NS & $\begin{array}{l}\text { Gender/Dx } \\
\text { F-BP } \\
\text { C:(4/21) } \\
0.78 / 4.44 \mathrm{E}-02 \\
\text { L:(3/11) } \\
1 / 7.15 \mathrm{E}-03\end{array}$ & $\begin{array}{l}\text { All } \\
\text { C:(102/470) } \\
0.57 / 1.03 \mathrm{E}-02 \\
\text { Gender } \\
\text { Males } \\
\text { C:(95/426) } \\
0.59 / 5.57 \mathrm{E}-03 \\
\text { Gender/Dx } \\
\text { M-MDD } \\
\text { C:(26/67) } \\
0.67 / 9.11 \mathrm{E}-03\end{array}$ & & $\begin{array}{l}\text { Alcohol } \\
\text { ASD } \\
\text { Circadian } \\
\text { abnormalities } \\
\text { Longevity } \\
\text { MDD } \\
\text { SZ }\end{array}$ & & 17 \\
\hline $\begin{array}{l}\text { EDNI } \\
\text { Endothelin } 1\end{array}$ & 1564630_at & $\begin{array}{l}\text { (I) } \\
\mathrm{AP} / 456 \%\end{array}$ & 4 & $\begin{array}{l}8.69 \mathrm{E}-02 / 2 \\
\text { Stepwise }\end{array}$ & & & $\begin{array}{l}\text { Gender } \\
\text { Females } \\
\text { C:(13/47) } \\
1.9 / 1.48 \mathrm{E}-02 \\
\text { Gender/Dx } \\
\text { M-BP } \\
\text { C:(53/134) } \\
1.27 / 2.37 \mathrm{E}-02\end{array}$ & & & 16 \\
\hline $\begin{array}{l}(\text { AF090920) } \\
\text { PPFIBP2 } \\
\text { PPFIA binding } \\
\text { protein } 2\end{array}$ & 234739_at & $\begin{array}{l}\text { (I) } \\
\mathrm{AP} / 6 \text { 94\% }\end{array}$ & 0 & NS & $\begin{array}{l}\text { Gender } \\
\text { Female } \\
\text { C:(16/65) } \\
0.68 / 1.42 \mathrm{E}-02 \\
\text { L:(10/36) } \\
0.69 / 3.87 \mathrm{E}-02 \\
\text { Gender/Dx } \\
\text { F-PTSD } \\
\text { C:(5/12) } \\
0.8 / 4.41 \mathrm{E}-02\end{array}$ & & $\begin{array}{l}\text { Gender/Dx } \\
\text { M-PSYCHOSIS } \\
\text { C:(95/201) } \\
\text { 1.19/3.77E-02 } \\
\text { M-SZ } \\
\text { C:(42/103) } \\
1.22 / 4.66 \mathrm{E}-02\end{array}$ & & & 16 \\
\hline $\begin{array}{l}D C A F 12 \\
\text { DDB1 and CUL4 } \\
\text { associated factor } 12\end{array}$ & 224789_at & $\begin{array}{l}\text { (D) } \\
\mathrm{DE} / 686 \%\end{array}$ & 2 & NS & $\begin{array}{l}\text { Gender/Dx } \\
\text { F-MDD } \\
\text { C:(2/18) } \\
1 / 1.23 \mathrm{E}-02\end{array}$ & & $\begin{array}{l}\text { Gender/Dx } \\
\text { M-BP } \\
\text { C:(53/134) } \\
1.61 / 4.42 \mathrm{E}-03\end{array}$ & $\begin{array}{l}\text { Cocaine } \\
\text { Suicide }\end{array}$ & $\begin{array}{l}\text { Omega-3 fatty } \\
\text { acids } \\
\text { Clozapine }\end{array}$ & 16 \\
\hline $\begin{array}{l}\text { DNAJC18 } \\
\text { DnaJ heat shock } \\
\text { protein family } \\
\text { (Hsp40) member } \\
\text { C18 }\end{array}$ & 227166_at & $\begin{array}{l}\text { (I) } \\
\mathrm{DE} / 694 \%\end{array}$ & 0 & NS & $\begin{array}{l}\text { Gender } \\
\text { Female } \\
\text { L:(10/36) } \\
0.78 / 4.97 \mathrm{E}-03 \\
\text { Gender/Dx } \\
\text { F-SZA } \\
\text { L:(3/8) } \\
0.93 / 2.63 \mathrm{E}-02 \\
\text { F-BP } \\
\text { L:(3/11) } \\
0.88 / 3.31 \mathrm{E}-02 \\
\text { F-PSYCHOSIS } \\
\text { L:(3/8) } \\
0.93 / 2.63 \mathrm{E}-02 \\
\text { F-PTSD } \\
\text { L:(3/6) } \\
\text { 1/2.48E-02 }\end{array}$ & $\begin{array}{l}\text { Gender/Dx } \\
\text { F-MDD } \\
\text { C:(4/11) } \\
0.93 / 1.17 \mathrm{E}-02\end{array}$ & & $\mathrm{BP}$ & & 16 \\
\hline $\begin{array}{l}\text { HLA-DRBI } \\
\text { Major } \\
\text { histocompatibility } \\
\text { complex, class II, } \\
\text { DR Beta 1 }\end{array}$ & 208306_x_at & $\begin{array}{l}\text { (I) } \\
\mathrm{AP} / 452 \%\end{array}$ & 4 & NS & $\begin{array}{l}\text { Gender/Dx } \\
\text { F-MDD } \\
\text { C:(2/18) } \\
0.91 / 3.39 \mathrm{E}-02 \\
\text { M-MDD } \\
\text { L:(13/43) } \\
0.66 / 4.79 \mathrm{E}-02 \\
\text { M-SZ } \\
\text { L:(7/39) } \\
0.71 / 4.27 \mathrm{E}-02\end{array}$ & $\begin{array}{l}\text { Gender/Dx } \\
\text { M-SZA } \\
\text { C:(23/97) } \\
0.62 / 4.69 \mathrm{E}-02\end{array}$ & & $\begin{array}{l}\text { Stress } \\
\text { PTSD }\end{array}$ & Antipsychotics & 16 \\
\hline $\begin{array}{l}\text { SEPT7P2 } \\
\text { Septin } 7 \\
\text { pseudogene } 2\end{array}$ & 1569973_at & $\begin{array}{l}\text { (I) } \\
\mathrm{DE} / \mathbf{6} \\
\mathbf{1 0 0 \%} \\
\text { (I) } \\
\mathrm{AP} / 239 \%\end{array}$ & 0 & NS & $\begin{array}{l}\text { Gender } \\
\text { Females } \\
\text { C:(16/65) } \\
0.65 / 3.27 \mathrm{E}-02 \\
\text { Gender/Dx } \\
\text { F-PTSD } \\
\text { C:(5/12) } \\
0.97 / 3.69 \mathrm{E}-03 \\
\text { M-SZ } \\
\text { C:(11/64) } \\
0.77 / 2.83 \mathrm{E}-03\end{array}$ & & $\begin{array}{l}\text { Gender/Dx } \\
\text { M-MDD } \\
\text { C:(42/72) } \\
1.45 / 1.37 \mathrm{E}-02 \\
\text { L:(25/43) } \\
2.25 / \mathbf{5 . 2 4 E - 0 4}{ }^{\mathrm{a}} \\
\text { M-PTSD } \\
\text { C:(26/31) } \\
2.38 / 7.38 E-04 \\
\text { L:(18/20) } \\
3.59 / 1.77 \mathrm{E}-03\end{array}$ & Suicide & & 16 \\
\hline $\begin{array}{l}\text { VEGFA } \\
\text { Vascular } \\
\text { endothelial growth } \\
\text { factor A }\end{array}$ & 212171_x_at & $\begin{array}{l}\text { (I) } \\
\mathrm{AP} / 465 \%\end{array}$ & 4 & NS & $\begin{array}{l}\text { Gender/Dx } \\
\text { M-PSYCHOSIS } \\
\text { C:(19/96) } \\
0.66 / 1.78 \mathrm{E}-02 \\
\text { M-SZA } \\
\text { C:(8/32) } \\
0.7 / 4.48 \mathrm{E}-02\end{array}$ & & $\begin{array}{l}\text { Gender/Dx } \\
\text { M-MDD } \\
\text { C:(42/72) } \\
1.33 / 4.83 \mathrm{E}-02\end{array}$ & $\begin{array}{l}\text { BP } \\
\text { MDD } \\
\text { Stress } \\
\text { SZ }\end{array}$ & $\begin{array}{l}\text { Lithium } \\
\text { Valproate } \\
\text { Olanzapine }\end{array}$ & 16 \\
\hline
\end{tabular}


Table 2 (continued)

\begin{tabular}{|c|c|c|c|c|c|c|c|c|c|c|}
\hline $\begin{array}{l}\text { Gene symbol/gene } \\
\text { name }\end{array}$ & Probesets & $\begin{array}{l}\text { Step 1 } \\
\text { Discovery } \\
\text { in blood } \\
\text { (direction } \\
\text { of change) } \\
\text { Method/ } \\
\text { score/\% } \\
\text { Up to } 6 \text { pts }\end{array}$ & $\begin{array}{l}\text { Step 2 } \\
\text { External } \\
\text { convergent } \\
\text { functional } \\
\text { genomics } \\
\text { (CFG) } \\
\text { Evidence for } \\
\text { involvement } \\
\text { in pain score } \\
\text { Up to } 12 \text { pts }\end{array}$ & $\begin{array}{l}\text { Step } 3 \\
\text { Validation } \\
\text { in blood } \\
\text { ANOVA } \\
p \text {-value/ } \\
\text { score Up } \\
\text { to } 6 \text { pts }\end{array}$ & $\begin{array}{l}\text { Step } 4 \\
\text { Best significant } \\
\text { prediction of } \\
\text { State-High Pain } \\
\text { (Cases/Total) } \\
\text { ROC AUC/ } \\
\text { p-value } \\
8 \text { pts All } \\
6 \text { pts Gender } \\
4 \text { pts Gender/Dx }\end{array}$ & $\begin{array}{l}\text { Step } 4 \\
\text { Best Significant } \\
\text { prediction of } \\
\text { Trait-Future ED } \\
\text { visits for Pain in } \\
\text { the first year } \\
\text { (Cases/Total) } \\
\text { ROC AUC/ } \\
\text { p-value } \\
8 \text { pts All } \\
6 \text { pts Gender } \\
4 \text { pts Gender/Dx }\end{array}$ & $\begin{array}{l}\text { Step } 4 \\
\text { Best significant predictions } \\
\text { of Trait- Future ED visits for } \\
\text { Pain in all future years } \\
\text { (Cases/Total) } \\
\text { OR/OR } p \text {-value } \\
8 \text { pts All } \\
6 \text { pts Gender } \\
4 \text { pts Gender/Dx }\end{array}$ & $\begin{array}{l}\text { Step } 5 \\
\text { Other psychiatric } \\
\text { and related } \\
\text { disorders evidence }\end{array}$ & $\begin{array}{l}\text { Step } 6 \\
\text { Drugs That } \\
\text { Modulate the } \\
\text { Biomarker in } \\
\text { opposite } \\
\text { Direction to } \\
\text { Pain }\end{array}$ & $\begin{array}{l}\mathrm{CFE} \\
\text { Polyevidence } \\
\text { score for } \\
\text { involvement in } \\
\text { pain (based on } \\
\text { steps 1-4) }\end{array}$ \\
\hline $\begin{array}{l}\text { WNKI } \\
\text { WNK lysine } \\
\text { deficient protein } \\
\text { kinase } 1\end{array}$ & 1555068_at & $\begin{array}{l}\text { (D) } \\
\mathrm{DE} / 692 \%\end{array}$ & 2 & NS & $\begin{array}{l}\text { Gender/Dx } \\
\text { M-MDD } \\
\text { L:(13/43) } \\
0.77 / 2.75 E-03\end{array}$ & & $\begin{array}{l}\text { Gender/Dx } \\
\text { M-BP } \\
\text { C:(53/134) } \\
1.41 / 3.18 \mathrm{E}-02\end{array}$ & $\begin{array}{l}\text { Alcohol } \\
\text { Depression } \\
\text { Suicide } \\
\text { Methamphetamine } \\
\text { Stress }\end{array}$ & $\begin{array}{l}\text { Omega-3 Fatty } \\
\text { acids } \\
\text { SSRI }\end{array}$ & 16 \\
\hline $\begin{array}{l}\text { (AF087971) } \\
\text { PBRM1 Polybromo } \\
1\end{array}$ & 1561067_at & $\begin{array}{l}\text { (I) } \\
\mathrm{AP} / 690 \%\end{array}$ & 0 & NS & & $\begin{array}{l}\text { All } \\
\text { C:(102/470) } \\
0.56 / 3.71 \mathrm{E}-02 \\
\text { Gender } \\
\text { Males } \\
\text { C:(95/426) } \\
0.56 / 2.87 \mathrm{E}-02 \\
\text { Gender/Dx } \\
\text { M-BP } \\
\text { C:(18/120) } \\
\text { 0.63/3.95E-02 } \\
\text { M-PSYCHOSIS } \\
\text { C:(33/198) } \\
\text { 0.63/8.63E-03 } \\
\text { M-SZA } \\
\text { C:(23/97) } \\
\text { 0.66/1.26E-02 }\end{array}$ & & $\begin{array}{l}\text { BP } \\
\text { Hallucinations } \\
\text { Longevity } \\
\text { MDD } \\
\text { Methamphetamine } \\
\text { Mood psychosis } \\
\text { Stress } \\
\text { Suicide }\end{array}$ & & 14 \\
\hline $\begin{array}{l}\text { (Hs.609761) SFPQ } \\
\text { Splicing factor } \\
\text { proline and } \\
\text { glutamine rich }\end{array}$ & 244331_at & $\begin{array}{l}\text { (D) } \\
\mathrm{DE} / 698 \%\end{array}$ & 0 & NS & $\begin{array}{l}\text { Gender/Dx } \\
\text { M-SZ } \\
\text { C:(11/64) } \\
0.68 / 3.28 \mathrm{E}-02 \\
\text { L:(7/39) } \\
0.75 / 2.21 \mathrm{E}-02\end{array}$ & & $\begin{array}{l}\text { Gender/Dx } \\
\text { M-MDD } \\
\text { C:(42/72) } \\
1.68 / 7.35 \mathrm{E}-03\end{array}$ & $\begin{array}{l}\text { Alcohol } \\
\text { BP } \\
\text { MDD } \\
\text { Stress } \\
\text { Suicide }\end{array}$ & $\begin{array}{l}\text { Omega-3 fatty } \\
\text { acids } \\
\text { Clozapine } \\
\text { Antidepressants } \\
\text { Antipsychotics }\end{array}$ & 14 \\
\hline $\begin{array}{l}\text { (Hs.659426) PHC3 } \\
\text { Polyhomeotic } \\
\text { homolog } 3\end{array}$ & 240599_x_at & $\begin{array}{l}\text { (D) } \\
\mathrm{DE} / 692 \%\end{array}$ & 0 & NS & $\begin{array}{l}\text { Gender/Dx } \\
\text { F-MDD } \\
\text { C:(2/18) } \\
0.91 / 3.39 \mathrm{E}-02\end{array}$ & & $\begin{array}{l}\text { Gender/Dx } \\
\text { M-MDD } \\
\text { C:(42/72) } \\
1.48 / 1.83 \mathrm{E}-02\end{array}$ & Suicide & & 14 \\
\hline $\begin{array}{l}C C D C 85 C \\
\text { Coiled-coil domain } \\
\text { containing } 85 \mathrm{C}\end{array}$ & 219018_s_at & $\begin{array}{l}\text { (D) } \\
\mathrm{DE} / 694 \%\end{array}$ & 2 & NS & $\begin{array}{l}\text { Gender } \\
\text { Female } \\
\text { L:(10/36) } \\
0.7 / 3.31 \mathrm{E}-02 \\
\text { Gender/Dx } \\
\text { F-BP } \\
\text { C:(4/21) } \\
0.79 / 3.66 \mathrm{E}-02 \\
\text { L:(3/11) } \\
0.92 / 2.06 \mathrm{E}-02 \\
\text { F-PTSD } \\
\text { L:(3/6) } \\
\text { 1/2.48E-02 }\end{array}$ & & & Suicide & & 14 \\
\hline $\begin{array}{l}\text { GSPTI } \\
\text { G1 To S phase } \\
\text { transition } 1\end{array}$ & 215438_x_at & $\begin{array}{l}\text { (D) } \\
\mathrm{DE} / 694 \%\end{array}$ & 0 & NS & $\begin{array}{l}\text { Gender/Dx } \\
\text { F-MDD } \\
\text { C:(2/18) } \\
1 / 1.23 \mathrm{E}-02\end{array}$ & & $\begin{array}{l}\text { Gender/Dx } \\
\text { M-BP } \\
\text { C:(53/134) } \\
1.58 / 4.92 \mathrm{E}-03\end{array}$ & $\begin{array}{l}\text { BP } \\
\text { Suicide } \\
\text { MDD }\end{array}$ & Valproate & 14 \\
\hline $\begin{array}{l}H L A-D Q B 1 \\
\text { Major } \\
\text { histocompatibility } \\
\text { complex, class II, } \\
\text { DQ Beta 1 }\end{array}$ & 211654_x_at & $\begin{array}{l}\text { (I) } \\
\mathrm{DE} / 240 \%\end{array}$ & 8 & NS & $\begin{array}{l}\text { Gender/Dx } \\
\text { M-PSYCHOSIS } \\
\text { L:(10/56) } \\
0.73 / 1.23 \mathrm{E}-02 \\
\text { M-SZ } \\
\text { L:(7/39) } \\
0.81 / 5.78 \mathrm{E}-03\end{array}$ & & & $\begin{array}{l}\text { Alcohol } \\
\text { BP } \\
\text { Depression } \\
\text { Longevity } \\
\text { PTSD } \\
\text { Stress } \\
\text { Suicide } \\
\text { SZ }\end{array}$ & Antipsychotics & 14 \\
\hline $\begin{array}{l}L O X L 2 \\
\text { Lysyl oxidase like } 2\end{array}$ & 228808_s_at & $\begin{array}{l}\text { (D) } \\
\mathrm{DE} / 459 \%\end{array}$ & 4 & NS & $\begin{array}{l}\text { Gender } \\
\text { Females } \\
\text { C:(16/65) } \\
0.66 / 3.05 \mathrm{E}-02 \\
\text { Gender/Dx } \\
\text { F-MDD } \\
\text { C:(2/18) } \\
1 / 1.23 \mathrm{E}-02\end{array}$ & & & $\begin{array}{l}\text { BP } \\
\text { Suicide }\end{array}$ & & 14 \\
\hline $\begin{array}{l}\text { MBNL3 } \\
\text { Muscleblind like } \\
\text { splicing regulator } 3\end{array}$ & 219814_at & $\begin{array}{l}\text { (D) } \\
\mathrm{DE} / 692 \%\end{array}$ & 0 & NS & $\begin{array}{l}\text { Gender/Dx } \\
\text { M-MDD } \\
\text { L:(13/43) } \\
0.71 / 1.51 \mathrm{E}-02\end{array}$ & & $\begin{array}{l}\text { Gender/Dx } \\
\text { M-BP } \\
\text { C:(53/134) } \\
1.43 / 8.16 \mathrm{E}-03\end{array}$ & $\begin{array}{l}\text { Psychosis } \\
\text { Hallucination }\end{array}$ & & 14 \\
\hline $\begin{array}{l}\text { PTN } \\
\text { Pleiotrophin }\end{array}$ & 211737_x_at & $\begin{array}{l}\text { (D) } \\
\mathrm{DE} / 692 \%\end{array}$ & 0 & NS & & & $\begin{array}{l}\text { All } \\
\text { C:(239/501) } \\
1.16 / 1.17 \mathrm{E}-02 \\
\text { Gender } \\
\text { Males } \\
\text { C:(226/454) } \\
1.2 / 4.66 \mathrm{E}-03 \\
\text { Gender/Dx }\end{array}$ & $\begin{array}{l}\text { SZ } \\
\text { Stress } \\
\text { Suicide }\end{array}$ & $\begin{array}{l}\text { Omega-3 fatty } \\
\text { acids } \\
\text { Risperidone }\end{array}$ & 14 \\
\hline
\end{tabular}


Table 2 (continued)

\begin{tabular}{|c|c|c|c|c|c|c|c|c|c|c|}
\hline $\begin{array}{l}\text { Gene symbol/gene } \\
\text { name }\end{array}$ & Probesets & $\begin{array}{l}\text { Step 1 } \\
\text { Discovery } \\
\text { in blood } \\
\text { (direction } \\
\text { of change) } \\
\text { Method/ } \\
\text { score/\% } \\
\text { Up to } 6 \text { pts }\end{array}$ & $\begin{array}{l}\text { Step } 2 \\
\text { External } \\
\text { convergent } \\
\text { functional } \\
\text { genomics } \\
\text { (CFG) } \\
\text { Evidence for } \\
\text { involvement } \\
\text { in pain score } \\
\text { Up to } 12 \text { pts }\end{array}$ & $\begin{array}{l}\text { Step } 3 \\
\text { Validation } \\
\text { in blood } \\
\text { ANOVA } \\
p \text {-value/ } \\
\text { score Up } \\
\text { to } 6 \text { pts }\end{array}$ & $\begin{array}{l}\text { Step } 4 \\
\text { Best significant } \\
\text { prediction of } \\
\text { State-High Pain } \\
\text { (Cases/Total) } \\
\text { ROC AUC/ } \\
p \text {-value } \\
8 \text { pts All } \\
6 \text { pts Gender } \\
4 \text { pts Gender/Dx }\end{array}$ & $\begin{array}{l}\text { Step } 4 \\
\text { Best Significant } \\
\text { prediction of } \\
\text { Trait-Future ED } \\
\text { visits for Pain in } \\
\text { the first year } \\
\text { (Cases/Total) } \\
\text { ROC AUC/ } \\
\text { p-value } \\
8 \text { pts All } \\
6 \text { pts Gender } \\
4 \text { pts Gender/Dx }\end{array}$ & $\begin{array}{l}\text { Step } 4 \\
\text { Best significant predictions } \\
\text { of Trait- Future ED visits for } \\
\text { Pain in all future years } \\
\text { (Cases/Total) } \\
\text { OR/OR } p \text {-value } \\
8 \text { pts All } \\
6 \text { pts Gender } \\
4 \text { pts Gender/Dx }\end{array}$ & $\begin{array}{l}\text { Step } 5 \\
\text { Other psychiatric } \\
\text { and related } \\
\text { disorders evidence }\end{array}$ & $\begin{array}{l}\text { Step } 6 \\
\text { Drugs That } \\
\text { Modulate the } \\
\text { Biomarker in } \\
\text { opposite } \\
\text { Direction to } \\
\text { Pain }\end{array}$ & $\begin{array}{l}\text { CFE } \\
\text { Polyevidence } \\
\text { score for } \\
\text { involvement in } \\
\text { pain (based on } \\
\text { steps 1-4) }\end{array}$ \\
\hline $\begin{array}{l}\text { RALGAPA2 } \\
\text { Ral GTPase } \\
\text { activating protein } \\
\text { catalytic alpha } \\
\text { subunit } 2\end{array}$ & 231826_at & $\begin{array}{l}\text { (D) } \\
\mathrm{DE} / 697 \%\end{array}$ & 0 & NS & $\begin{array}{l}\text { Gender/Dx } \\
\text { F-MDD } \\
\text { C:(2/18) } \\
0.94 / 2.46 \mathrm{E}-02\end{array}$ & & $\begin{array}{l}\text { M-PSYCHOSIS } \\
\text { C:(95/201) } \\
1.24 / 1.98 \mathrm{E}-02 \\
\text { M-SZA } \\
\text { C:(53/98) } \\
1.35 / 1.28 \mathrm{E}-02 \\
\text { Gender/Dx } \\
\text { M-MDD } \\
\text { C:(42/72) } \\
2.06 / 4.52 E-04^{\mathrm{a}} \\
\text { L:(25/43) } \\
2.05 / 5.35 \mathrm{E}-03\end{array}$ & $\mathrm{BP}$ & & 14 \\
\hline $\begin{array}{l}Y B X 3 \\
\text { Y-Box binding } \\
\text { protein } 3\end{array}$ & 201160_s_at & $\begin{array}{l}\text { (D) } \\
\mathrm{DE} / 694 \%\end{array}$ & 0 & NS & $\begin{array}{l}\text { Gender/Dx } \\
\text { F-MDD } \\
\text { C:(2/18) } \\
0.97 / 1.75 \mathrm{E}-02\end{array}$ & & $\begin{array}{l}\text { Gender/Dx } \\
\text { M-BP } \\
\text { C:(53/134) } \\
1.39 / 1.23 \mathrm{E}-02\end{array}$ & $\begin{array}{l}\text { BP } \\
\text { Suicide } \\
\text { SZ }\end{array}$ & Mianserin & 14 \\
\hline $\begin{array}{l}Z N F 441 \\
\text { Zinc finger protein } \\
441\end{array}$ & 1553193_at & $\begin{array}{l}\text { (I) } \\
\mathrm{AP} / 695 \% \\
\text { (I) } \\
\mathrm{DE} / 235 \%\end{array}$ & 0 & NS & & $\begin{array}{l}\text { Gender/Dx } \\
\text { M-SZA } \\
\text { L:(13/55) } \\
0.67 / 3.13 E-02\end{array}$ & $\begin{array}{l}\text { Gender/Dx } \\
\text { M-MDD } \\
\text { L:(25/43) } \\
1.72 / 1.92 \mathrm{E}-02\end{array}$ & & & 14 \\
\hline $\begin{array}{l}\text { CCND1 } \\
\text { Cyclin D1 }\end{array}$ & 208712_at & $\begin{array}{l}\text { (D) } \\
\mathrm{DE} / 457 \%\end{array}$ & 4 & NS & & & $\begin{array}{l}\text { Gender/Dx } \\
\text { M-BP } \\
\text { C:(53/134) } \\
1.33 / 4.53 \mathrm{E}-02\end{array}$ & $\begin{array}{l}\text { Addiction } \\
\text { MDD } \\
\text { Stress } \\
\text { Hallucinogens }\end{array}$ & & 12 \\
\hline $\begin{array}{l}C D K 6 \\
\text { Cyclin-dependent } \\
\text { kinase } 6\end{array}$ & 224847_at & $\begin{array}{l}\text { (I) } \\
\mathrm{DE} / 463 \%\end{array}$ & 4 & NS & & & $\begin{array}{l}\text { Gender/Dx } \\
\text { M-PTSD } \\
\text { L:(18/20) } \\
2.09 / 1.75 E-02\end{array}$ & $\begin{array}{l}\text { Alcohol } \\
\text { ASD } \\
\text { Circadian } \\
\text { abnormalities } \\
\text { Longevity } \\
\text { MDD } \\
\text { SZ }\end{array}$ & & 12 \\
\hline $\begin{array}{l}\text { COMT } \\
\text { Catechol-O- } \\
\text { methyltransferase }\end{array}$ & 213981_at & $\begin{array}{l}\text { (D) } \\
\mathrm{DE} / 454 \%\end{array}$ & 4 & NS & $\begin{array}{l}\text { Gender/Dx } \\
\text { M-MDD } \\
\text { L:(13/43) } \\
0.71 / 1.41 \mathrm{E}-02\end{array}$ & & & $\begin{array}{l}\text { ADHD } \\
\text { Aggression } \\
\text { Alcohol } \\
\text { Anxiety } \\
\text { BP } \\
\text { Chronic stress } \\
\text { MDD } \\
\text { OCD } \\
\text { Panic disorder } \\
\text { Psychosis } \\
\text { PTSD } \\
\text { Suicide } \\
\text { SZ }\end{array}$ & $\begin{array}{l}\text { Clozapine } \\
\text { Morphine } \\
\text { Mood stabilizers }\end{array}$ & 12 \\
\hline $\begin{array}{l}\text { HTR } 2 A \\
5- \\
\text { Hydroxytryptamine } \\
\text { receptor } 2 \mathrm{~A}\end{array}$ & 211616_s_at & $\begin{array}{l}\text { (D) } \\
\mathrm{DE} / 452 \%\end{array}$ & 4 & NS & $\begin{array}{l}\text { Gender/Dx } \\
\text { M-BP } \\
\text { L:(16/81) } \\
0.65 / 2.89 \mathrm{E}-02\end{array}$ & & & $\begin{array}{l}\text { Addictions } \\
\text { Aging } \\
\text { Alcohol } \\
\text { Anxiety } \\
\text { BP } \\
\text { Depression } \\
\text { MDD } \\
\text { Mood disorders } \\
\text { NOS } \\
\text { OCD } \\
\text { Panic disorder } \\
\text { PTSD } \\
\text { Stress } \\
\text { Suicide } \\
\text { SZ }\end{array}$ & & 12 \\
\hline $\begin{array}{l}N F 1 \\
\text { Neurofibromin } 1\end{array}$ & 212676_at & $\begin{array}{l}\text { (I) } \\
\mathrm{DE} / 459 \%\end{array}$ & 4 & NS & $\begin{array}{l}\text { Gender/Dx } \\
\text { F-BP } \\
\text { L:(3/11) } \\
0.92 / 2.06 \mathrm{E}-02\end{array}$ & & & $\begin{array}{l}\text { Addiction } \\
\text { BP } \\
\text { PTSD }\end{array}$ & $\begin{array}{l}\text { Fluoxetine } \\
\text { SSRI }\end{array}$ & 12 \\
\hline $\begin{array}{l}\text { SHMT1 } \\
\text { Serine } \\
\text { hydroxymethyl- } \\
\text { transferase } 1\end{array}$ & 217304_at & $\begin{array}{l}\text { (D) } \\
\mathrm{DE} / 243 \%\end{array}$ & 6 & NS & & $\begin{array}{l}\text { Gender/Dx } \\
\text { F-PTSD } \\
\text { C:(2/8) } \\
1 / 2.28 \mathrm{E}-02 \\
\text { M-SZA } \\
\text { L:(13/55) } \\
0.7 / 1.54 \mathrm{E}-02\end{array}$ & & Suicide & Clozapine & 12 \\
\hline $\begin{array}{l}\text { TSPO } \\
\text { Translocator } \\
\text { protein }\end{array}$ & 202096_s_at & $\begin{array}{l}\text { (I) } \\
\mathrm{DE} / 238 \%\end{array}$ & 6 & NS & $\begin{array}{l}\text { Gender/Dx } \\
\text { M-SZ } \\
\text { C:(11/64) } \\
0.72 / 1.06 \mathrm{E}-02\end{array}$ & & & $\mathrm{SZ}$ & & 12 \\
\hline $\begin{array}{l}\text { DENNDIB } \\
\text { DENN domain } \\
\text { containing 1B }\end{array}$ & 1557309_at & $\begin{array}{l}\text { (I) } \\
\mathrm{DE} / 6 \\
90 \%\end{array}$ & 0 & NS & $\begin{array}{l}\text { Gender/Dx } \\
\text { M-SZA }\end{array}$ & & & & Omega-3 & 10 \\
\hline
\end{tabular}


Table 2 (continued)

\begin{tabular}{|c|c|c|c|c|c|c|c|c|c|c|}
\hline $\begin{array}{l}\text { Gene symbol/gene } \\
\text { name }\end{array}$ & Probesets & $\begin{array}{l}\text { Step 1 } \\
\text { Discovery } \\
\text { in blood } \\
\text { (direction } \\
\text { of change) } \\
\text { Method/ } \\
\text { score/\% } \\
\text { Up to } 6 \text { pts }\end{array}$ & $\begin{array}{l}\text { Step } 2 \\
\text { External } \\
\text { convergent } \\
\text { functional } \\
\text { genomics } \\
\text { (CFG) } \\
\text { Evidence for } \\
\text { involvement } \\
\text { in pain score } \\
\text { Up to } 12 \text { pts }\end{array}$ & $\begin{array}{l}\text { Step } 3 \\
\text { Validation } \\
\text { in blood } \\
\text { ANOVA } \\
p \text {-value/ } \\
\text { score Up } \\
\text { to } 6 \text { pts }\end{array}$ & $\begin{array}{l}\text { Step } 4 \\
\text { Best significant } \\
\text { prediction of } \\
\text { State-High Pain } \\
\text { (Cases/Total) } \\
\text { ROC AUC/ } \\
p \text {-value } \\
8 \text { pts All } \\
6 \text { pts Gender } \\
4 \text { pts Gender/Dx }\end{array}$ & $\begin{array}{l}\text { Step } 4 \\
\text { Best Significant } \\
\text { prediction of } \\
\text { Trait-Future ED } \\
\text { visits for Pain in } \\
\text { the first year } \\
\text { (Cases/Total) } \\
\text { ROC AUC/ } \\
p \text {-value } \\
8 \text { pts All } \\
6 \text { pts Gender } \\
4 \text { pts Gender/Dx }\end{array}$ & $\begin{array}{l}\text { Step } 4 \\
\text { Best significant predictions } \\
\text { of Trait- Future ED visits for } \\
\text { Pain in all future years } \\
\text { (Cases/Total) } \\
\text { OR/OR } p \text {-value } \\
8 \text { pts All } \\
6 \text { pts Gender } \\
4 \text { pts Gender/Dx }\end{array}$ & $\begin{array}{l}\text { Step } 5 \\
\text { Other psychiatric } \\
\text { and related } \\
\text { disorders evidence }\end{array}$ & $\begin{array}{l}\text { Step } 6 \\
\text { Drugs That } \\
\text { Modulate the } \\
\text { Biomarker in } \\
\text { opposite } \\
\text { Direction to } \\
\text { Pain }\end{array}$ & $\begin{array}{l}\text { CFE } \\
\text { Polyevidence } \\
\text { score for } \\
\text { involvement in } \\
\text { pain (based on } \\
\text { steps 1-4) }\end{array}$ \\
\hline $\begin{array}{l}\text { MCRSI } \\
\text { Microspherule } \\
\text { protein 1 }\end{array}$ & 202556_s_at & $\begin{array}{l}\text { (I) } \\
\mathrm{AP} / 240 \% \\
\text { (I) } \\
\mathrm{DE} / 690 \%\end{array}$ & 0 & NS & $\begin{array}{l}\text { L:(3/17) } \\
0.83 / 3.89 \mathrm{E}-02 \\
\text { Gender/Dx } \\
\text { M-MDD } \\
\text { L:(13/43) } \\
0.75 / 5.16 \mathrm{E}-03\end{array}$ & & & MDD & & 10 \\
\hline $\begin{array}{l}O S B P 2 \\
\text { Oxysterol binding } \\
\text { protein } 2\end{array}$ & 1569617_at & $\begin{array}{l}\text { (D) } \\
\mathrm{DE} / 694 \%\end{array}$ & 0 & NS & $\begin{array}{l}\text { Gender/Dx } \\
\text { F-MDD } \\
\text { C:(2/18) } \\
1 / 1.23 \mathrm{E}-02\end{array}$ & & & $\begin{array}{l}\text { Cocaine } \\
\text { Suicide } \\
\text { SZ }\end{array}$ & & 10 \\
\hline $\begin{array}{l}\text { FAM134B } \\
\text { Family with } \\
\text { sequence similarity } \\
134 \text { member B }\end{array}$ & 218510_x_at & $\begin{array}{l}\text { (I) } \\
\mathrm{DE} / 4 \\
51 \% ; \\
\text { (I) } \\
\mathrm{AP} / 234 \%\end{array}$ & 4 & NS & & & & $\begin{array}{l}\text { Antisocial } \\
\text { personality } \\
\text { Suicide }\end{array}$ & $\begin{array}{l}\text { Omega-3 fatty } \\
\text { acids }\end{array}$ & 8 \\
\hline $\begin{array}{l}\text { ZNF429 } \\
\text { Zinc finger protein } \\
429\end{array}$ & 1561270_at & $\begin{array}{l}\text { (D) } \\
\mathrm{DE} / 237 \%\end{array}$ & 6 & NS & & & & & & 8 \\
\hline $\begin{array}{l}\text { (Hs.677263) } \\
\text { SMURF2 } \\
\text { SMAD specific E3 } \\
\text { ubiquitin protein } \\
\text { ligase } 2\end{array}$ & 216444_at & $\begin{array}{l}\text { (D) } \\
\mathrm{AP} / 6 \\
100 \% \\
\text { (D) } \\
\mathrm{DE} / 471 \%\end{array}$ & 0 & NS & & & & $\begin{array}{l}\text { Aging } \\
\text { Suicide } \\
\text { Stress }\end{array}$ & & 6 \\
\hline
\end{tabular}

$D E$ differential expression, $A P$ absent/present, $N S$ non-stepwise in validation. For predictions, $C$-cross-sectional (using levels from one visit), $L$ longitudinal (using levels and slopes from multiple visits). In All, by Gender, and personalized by Gender and Diagnosis (Gender/Dx). $M$ males, $F$ Females, MDD depression, BP bipolar, SZ schizophrenia, SZA schizoaffective, PSYCHOSIS schizophrenia and schizoaffective combined, PTSD post-traumatic stress disorder.

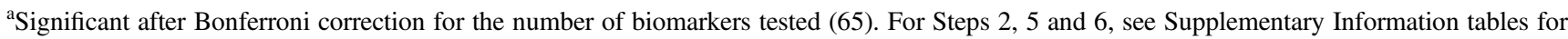
citations for the evidence.

did not work as well as individual biomarkers, particularly when the later are tested by gender and diagnosis, consistent with there being heterogeneity in the population and supporting the need for personalization. The notable exception was predicting longitudinally all future ED visits for pain, where the panel of five validated biomarkers performed better than individual biomarkers (Supplementary InformationComplete Analyses). Importantly, predictions of future ED visits for pain in the independent cohorts were consistently stronger using biomarkers than clinical phenotypic markers (pain VAS scale, pain items 21 and 22 from SF 36) (see Supplementary Information-Complete Analyses), supporting the utility of biomarkers.

Fifth, we assessed if our biomarkers have evidence for involvement in other psychiatric and related disorders (Table S3). A majority of our biomarkers have some evidence in other disorders, whereas a few seem to be specific for pain, such as CCDC144B (Coiled-Coil Domain Containing 144B), COL2A1 (Collagen Type II Alpha 1 Chain), PPFIBP2 (PPFIA Binding Protein 2), DENND1B (DENN Domain Containing 1B), ZNF441 (Zinc Finger Protein 441), TOP3A (Topoisomerase (DNA) III Alpha), and ZNF429 (Zinc Finger Protein 429). A majority of our biomarkers (50 out of 60 genes, i.e., 83.3\%) have prior evidence for involvement in suicide, suggesting an extensive molecular co-morbidity between pain and suicide, to go along with the clinical and phenomenological co-morbidity (physical pain, psychic pain) [15]. We also analyzed the biological pathways and networks our biomarkers are involved in (Table S4 and Fig. 3). There is a network centered on GNG7 (Fig. 3), that may be involved in connectivity/signaling, comprising HTR2A, EDN1, PNOC (involved in pain signaling) and CALCA (involved in Reflex Sympathetic Dystrophy and Complex Regional Pain Syndrome). It is reassuring that we see PNOC (Prepronociceptin) increased in expression in high pain states, i.e., as an algogene. Given its known roles in pain, it serves as a de facto positive control. A second network is centered on CCND1, may be involved in activity/trophicity, and comprises HRAS, CDK6, PBRM1, CSDA, LOXL2, EDN1, PIK3CD, and VEGFA. A third network is centered on HLA DRB1, may be involved in reactivity/immune response, and comprises GBP1, ZNF429, COL2A1, and HLA DQB1, from our list of 65 top biomarkers.

Sixth, we identified which of our biomarkers are targets of existing drugs and thus can be used for pharmacogenomics population stratification and measuring of response to treatment (Table 2 and Table S5), as well as used the biomarker gene expression signature to interrogate the Connectivity Map database from Broad/MIT to identify drugs and natural 
A Predictions for State - High Pain State

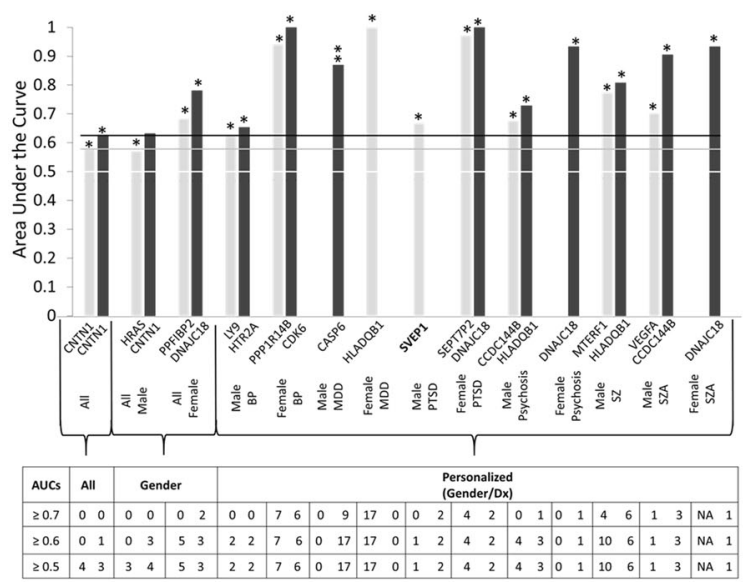

B Predictions for Trait- Future ED visits for Pain- First Year $₫$ Cross-sectional
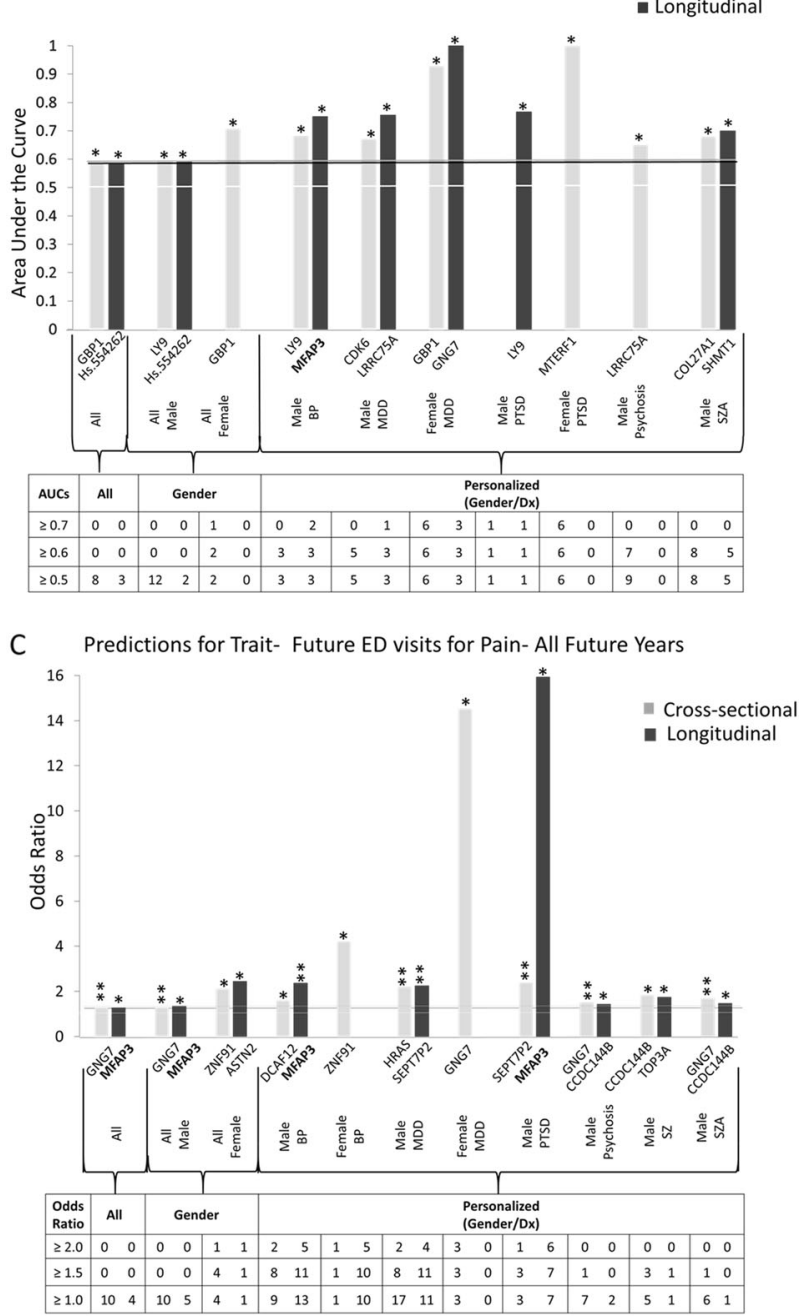

compounds that can be repurposed for treating pain (Table 3). The top drugs identified as potential new pain therapeutic is SC-560, an NSAID, haloperidol, and antipsychotic, and amoxapine, an antidepressant. The top natural compounds
Fig. 2 Best single biomarkers predictors. From the long list $(n=65)$. Those on short list $(n=5)$ are bolded. Bar graph shows best predictive biomarkers in each group. *Nominally significant $p<0.05$. **Bonferroni significant for the 65 biomarkers tested. Table underneath the figures displays the actual number of biomarkers for each group whose ROC AUC $p$-values $(\mathbf{a}, \mathbf{b})$ and Cox odds ratio $p$-values (c) are at least nominally significant. Some female diagnostic group are missing from the graph as they did not have any significant biomarkers. Crosssectional is based on levels at one visit. Longitudinal is based on levels at multiple visits (integrates levels at most recent visit, maximum levels, slope into most recent visit, and maximum slope). Dividing lines represent the cutoffs for a test performing at chance levels (white), and at the same level as the best biomarkers for all subjects in cross-sectional (gray) and longitudinal (black) based predictions. All biomarkers perform better than chance. Biomarkers performed better when personalized by gender and diagnosis

were pyridoxine (vitamin B6), cyanocobalamin (vitamin B12), and apigenin (a plant flavonoid).

\section{Discussion}

Biomarkers are emerging as important tools in disorders where subjective self-report of an individual and/or clinical impression of a healthcare professional are not always reliable. Recent work by our group has identified blood gene expression biomarkers that track suicidality using powerful longitudinal within-subject designs, validated them in suicide completers, and tested them in independent cohorts demonstrating their ability to predict state (suicidal ideation), and to predict trait (future hospitalizations for suicidality) (Niculescu et al. [7], Levey et al. [2], Niculescu et al. $[8,11])$. Similar to suicidality, pain is a subjective feeling, with objective roots. It may reflect past or current injury events, their adverse consequences and compensatory mechanisms. The rationale for identifying validated and reproducible blood biomarkers is precisely because you cannot directly biopsy brain and spinal centers of pain perception. Blood biomarkers are easily accessible, and constitute a surrogate (liquid biopsy).

We present work employing a powerful longitudinal within-subject design, previously described by us for suicidality [6-12], and used now to discover blood gene expression changes between self-reported low pain and high pain states. Gene expression is more powerful than genetics, as it integrates a multitude of genetic variants and environmental effects. Longitudinal within-subject designs are more powerful than case-control designs, and can provide information with small Ns, as illustrated and discussed by Snyder and colleagues [16-18], as well as Schork, Topol, and colleagues $[19,20]$. Some of these candidate gene expression biomarkers are increased in expression in high pain states (being putative risk genes), and others are decreased in expression (being putative protective/resilience genes). We cannot readily differentiate with our 


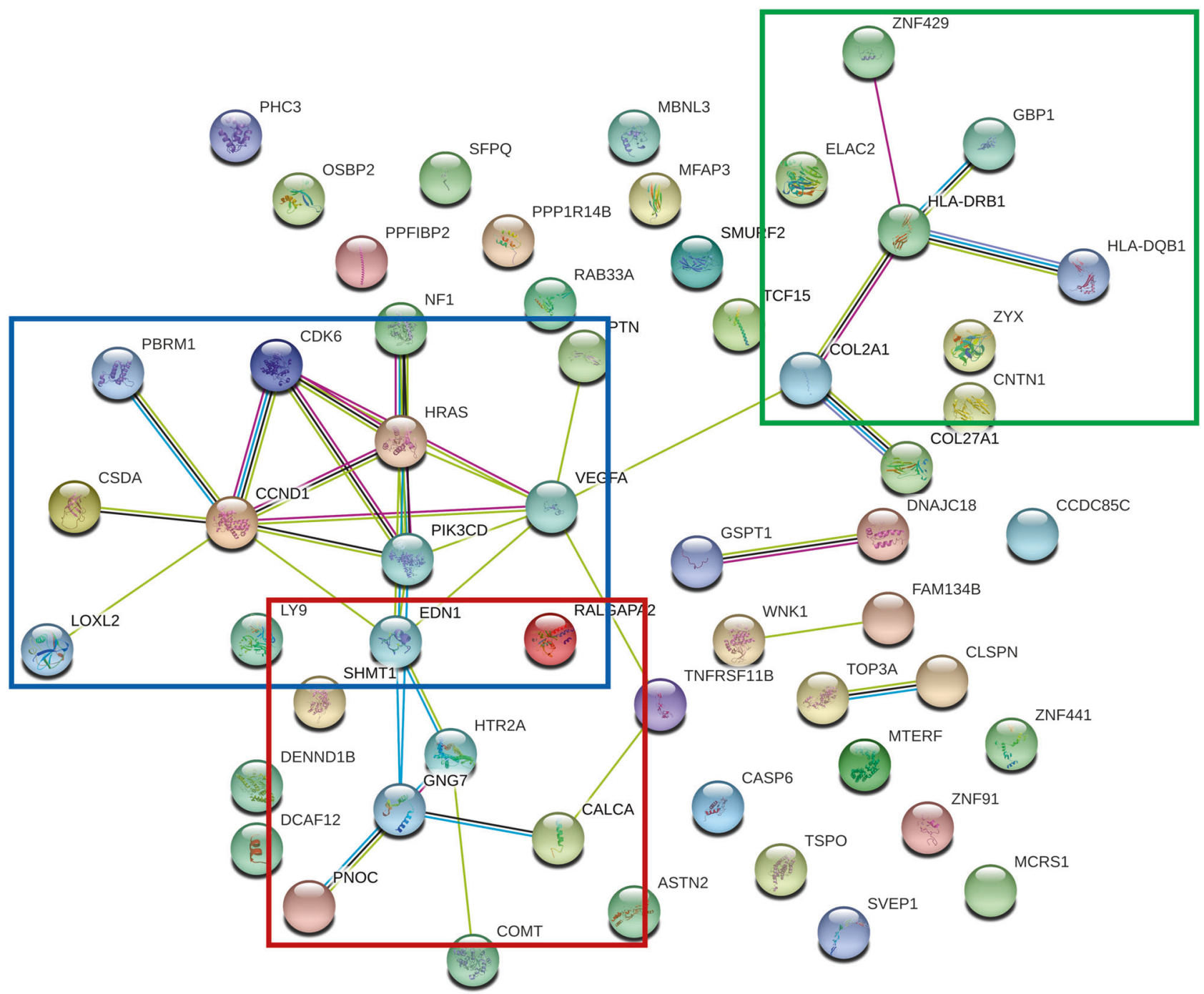

Fig. 3 Biological roles. STRING interaction network for the top biomarkers for pain ( 65 probesets, 60 genes)

observational studies which of them are a reflection of damage and which are compensatory mechanisms. However, given the fact that these biomarkers are discovered in Step 1 by tracking present/state changes in the perception of pain and not past/trait exposure, they may be more likely a reflection of pathogenesis rather than adaptation.

Our systematic approach led to the identification of objective predictive biomarkers for pain, state and trait. We present evidence for universal biomarkers for pain, as well as show evidence that personalization by gender and diagnosis enhances precision, going from AUCs over $60 \%$ to AUCs over $80 \%$. A majority of the top biomarkers we have identified overlap with biomarkers previously identified by us in suicide, and almost all have evidence in other psychiatric disorders (Table S3). Overlap and co-morbidity of genetic findings are in general the rule, not the exception, for neuropsychiatric disorders. Given the fact that pain disorders and psychiatric disorders are highly co-morbid clinically, that psychiatric medications are used to treat pain, and that pain medications can have psychiatric effects, the overlap is perhaps not surprising. It underlies the comorbidity and impact of pain on mental health and on suicidality. Indeed, mood disorders were among the top diseases identified by pathway analyses of our pain biomarker data (Table S4B).

The biomarkers with the best overall convergent information evidence (CFE) across the multiple steps were GNG7, CNTN1, LY9, CCDC144B, GBP1, and MFAP3 (Table 2). GNG7 (G Protein Subunit Gamma 7), with roles in signal transduction, is decreased in expression in blood in High Pain states in our work, i.e., it is a pain suppressor gene. GNG7 is a strong predictor in the independent cohorts, particularly for all future ED visits for pain. There is evidence in other tissues in human studies for involvement in pain (diabetic neuropathy [21], vertebral disc [22]). GNG7 is a strong predictor in the independent cohorts, particularly for 
Table 3 Therapeutics

\begin{tabular}{|c|c|c|c|}
\hline Rank & CMAP name & Score & Description \\
\hline 1 & SC-560 & -1 & $\begin{array}{l}\text { SC-560 is an NSAID, member of the diaryl heterocycle class of cyclooxygenase (COX) inhibitors which } \\
\text { includes celecoxib }\left(\text { Celebrex }{ }^{\mathrm{TM}}\right) \text { and rofecoxib }\left(\operatorname{Vioxx}^{\mathrm{TM}}\right) \text {. However, unlike these selective COX-2 inhibitors, } \\
\text { SC-560 is a selective inhibitor of COX-1. }\end{array}$ \\
\hline 2 & Pyridoxine & -0.997 & $\begin{array}{l}\text { Pyridoxine is the 4-methanol form of vitamin B6 and is converted to pyridoxal 5-phosphate in the body. } \\
\text { Pyridoxal 5-phosphate is a coenzyme for synthesis of amino acids, neurotransmitters (serotonin, } \\
\text { norepinephrine), sphingolipids, aminolevulinic acid. }\end{array}$ \\
\hline 3 & Methylergometrine & -0.975 & $\begin{array}{l}\text { Methylergometrine is a synthetic analog of ergonovine, a psychedelic alkaloid found in ergot, and many } \\
\text { species of morning glory. It is chemically similar to LSD, ergine, ergometrine, and lysergic acid. Due to its } \\
\text { oxytocic properties, it has a medical use in obstetrics. }\end{array}$ \\
\hline 4 & LY-294002 & -0.923 & $\begin{array}{l}\text { LY-294002 is a potent, cell permeable inhibitor of phosphatidylinositol 3-kinase (PI3K) that acts on the ATP } \\
\text { binding site of the enzyme. The PI3K pathway has a role in inhibiting apoptosis in cancer. PI3K is also known } \\
\text { to regulate TLR-mediated inflammatory responses. }\end{array}$ \\
\hline 5 & Haloperidol & -0.917 & Widely used typical antipsychotic medication \\
\hline 6 & Cytisine & -0.909 & $\begin{array}{l}\text { Like varenicline, cytisine is a partial agonist of nicotinic acetylcholine receptors (nAChRs), with an affinity for } \\
\text { the } \alpha 4 \beta 2 \text { receptor subtype, and a half-life of } 4.8 \mathrm{~h} \text {. }\end{array}$ \\
\hline 7 & Cyanocobalamin & -0.902 & $\begin{array}{l}\text { Cyanocobalamin is a form of vitamin B12. Vitamin B12 is important for growth, cell reproduction, blood } \\
\text { formation, and protein and tissue synthesis. }\end{array}$ \\
\hline 8 & Apigenin & -0.899 & $\begin{array}{l}\text { Apigenin }\left(4^{\prime}, 5,7 \text {-trihydroxyflavone), found in many plants such as chamomile, is a natural product belonging }\right. \\
\text { to the flavone class. Apigenin acts as a monoamine transporter activator, and is a weak ligand for central } \\
\text { benzodiazepine receptors in vitro and exerts anxiolytic and slight sedative effects in an animal model. It has } \\
\text { also effects on adenosine receptors and is an acute antagonist at the NMDA receptors (IC50=10 } \mu \mathrm{M}) \text {. In } \\
\text { addition, like various other flavonoids, apigenin has been found to possess nanomolar affinity for the opioid } \\
\text { receptors, acting as a non-selective antagonist of all three opioid receptors. }\end{array}$ \\
\hline 9 & Beta-escin & -0.892 & $\begin{array}{l}\text { Escin, a natural mixture of triterpenoid saponins isolated from horse chestnut (Aesculus hippocastanum) } \\
\text { seeds, is used and studied as a vasoprotective anti-inflammatory, anti-edematous, and anti-nociceptive agent. }\end{array}$ \\
\hline 13 & Amoxapine & -0.875 & $\begin{array}{l}\text { Amoxapine is a tricyclic antidepressant of the dibenzoxazepine class. This drug is used to treat symptoms of } \\
\text { depression and neuropathic pain. }\end{array}$ \\
\hline
\end{tabular}

New drug discovery/repurposing. Connectivity Map [43, 44] (CMAP) analysis- drugs that have opposite gene expression profile effects to our pain biomarkers signatures (i.e., best is -1). Out of 65 probesets, 14 of the 29 increased, and 19 of the 36 decreased were present in HG-U133A array used by Connectivity Map. A score of -1 indicates the perfect opposite match, i.e., the best potential therapeutic for pain. Drugs in Bold-drugs known to treat pain, which thus serve as a de facto positive control for our approach. Drugs in Italic—natural compounds

all future ED visits for pain. GNG7 also has trans-diagnostic evidence for involvement in other psychiatric disorders. It is decreased in expression in mouse brain by alcohol, hallucinogens, and stress [23, 24, 25], and increased in expression by omega-3 fatty acids. CNTN1 (Contactin 1), with roles in neuronal cell adhesion, is decreased in expression in blood in High Pain states in our work, i.e., it is a pain suppressor gene. Reassuringly, there is a possible mechanistic basis for its involvement in pain [26], and there is convergent evidence in other tissues in human studies for involvement in pain: CNTN1 has also been reported to be decreased in expression in CSF in women with chronic widespread pain (CWP) [27]. Anti-contactin 1 autoantibodies, that block/decrease levels of contactin 1 , have been described in chronic inflammatory demyelinating polyneuropathy [28]. Such reproducibility across studies, tissues and populations provides strong reasons to consider it as a bona fide marker for pain, and it serves as a reassuring de facto positive control for the design and power of our study. CNTN1 has also trans-diagnostic evidence for involvement in psychiatric disorders. It is decreased in expression in schizophrenia brain [29] and blood [30], and in blood in suicidality in females [8]. CNTN1 is increased in expression by clozapine in mouse brain [24]. LY9 (lymphocyte antigen 9), with immunomodulatory roles, is increased in expression in blood in High Pain states in our work, i.e., it is an algogene. LY9 is a good predictor in the independent cohorts for state and trait, particularly for males with MDD and PTSD. It also has epigenetic evidence for involvement in exposure to stress [31], and is decreased in expression by omega-3 fatty acids in mouse brain [32] CCDC144B (Coiled-Coil Domain Containing 144B) is decreased in expression in blood in High Pain states in our work. There is evidence in other tissues in human [33] and animal model [34] studies for involvement in pain. CCDC144B is a good predictor in the independent cohorts for state and trait, particularly for males with psychosis (SZ, SZA). It does not have trans-diagnostic evidence for involvement in other psychiatric disorders, seeming to be relatively specific for pain. GBP1 (guanylate binding protein 1), with interferon induced signaling roles, is increased in expression in blood in High Pain states in our work. There is other evidence in human studies, gene expression 
[33] and genetic [35], for involvement in pain. GBP1 is a predictor in the independent cohorts for trait, particularly in females. It is increased in expression in the brain in MDD [36], schizophrenia [37, 38], and suicide [36], and in blood in PTSD [39]. GBP1 is decreased in expression by omega-3 in mouse brain [40]. Hs.666804/MFAP3 (microfibril associated protein 3), another of the top markers, is a component of elastin-associated microfibrils. MFAP3 has the most robust empirical evidence from our discovery and validation steps, and is a strong predictor in the independent cohort, particularly for pain in females and males with PTSD. Interestingly, it has no prior evidence for pain in the literature curated to date for our Prioritization/CFG step, which demonstrates that we are casting a wide-enough net with our approach that can bring to the fore completely novel findings. MFAP3 is decreased in expression in blood in High Pain states in our work, i.e., it is a pain suppressor gene. It also has previous evidence for involvement in alcoholism [41], stress [42], and suicide [7, 9].

A phenotypic clustering analysis of the discovery cohort revealed two broad putative subtypes of High Pain states, a predominantly psychotic subtype, possibly related to mis-connectivity and increased perception of pain centrally, and a predominantly anxious subtype, possibly related to reactivity and increased physical health reasons for pain peripherally. Deeper analyses of the clustering in future studies may also substantiate further parsing of the subtypes, possibly into eight instead of only two subtypes, and of underlying differentiating biomarkers.

The biomarkers gene expression signatures also open the door to drug repurposing approaches, including of nutraceuticals. Nutraceuticals are particularly amenable to use in preventive population level approaches.

In conclusion, our work opens the door for precision medicine for pain, with objective diagnostics and targeted novel therapeutics. Given the massive negative impact of untreated pain on quality of life, the current lack of objective measures to determine appropriateness of treatment, and the severe addiction gateway potential of existing opioid-based pain medications, the importance of approaches such as ours cannot be overstated.

Acknowledgements This work is, in essence, a field-wide collaboration. We would like to acknowledge our debt of gratitude for the efforts and results of the many other groups, cited in our paper, who have conducted and published studies (clinical, genetic, and biological) in pain disorders. With their arduous and careful work, a convergent approach such as ours is possible. We would particularly like to thank the subjects who participated in these studies, their families and their caregivers. Without their contribution, such work to advance the understanding of pain would not be possible. This work was supported by an NIH Directors' New Innovator Award (1DP2OD007363) and a VA Merit Award (2I01CX000139) to ABN, and VA Merit Award (I01BX002209) to FAW.
Author contributions $\mathrm{ABN}$ designed the study and wrote the manuscript. HLN, DFL, KR, and JR analyzed the data. KCS and FK performed literature searches and database work. TJ, SJ, MM, ARW and AW organized, scored, and conducted testing in psychiatric subjects. SMK conducted microarray experiments and provided input on data analyses. FW assisted with data interpretation. All authors reviewed the final manuscript and agreed with it.

\section{Compliance with ethical standards}

Conflict of interest $\mathrm{ABN}$ is listed as inventor on a patent application being filed by Indiana University, and is a co-founder of MindX Sciences. The other authors declare that they have no conflict of interest.

Publisher's note: Springer Nature remains neutral with regard to jurisdictional claims in published maps and institutional affiliations.

Open Access This article is licensed under a Creative Commons Attribution 4.0 International License, which permits use, sharing, adaptation, distribution and reproduction in any medium or format, as long as you give appropriate credit to the original author(s) and the source, provide a link to the Creative Commons license, and indicate if changes were made. The images or other third party material in this article are included in the article's Creative Commons license, unless indicated otherwise in a credit line to the material. If material is not included in the article's Creative Commons license and your intended use is not permitted by statutory regulation or exceeds the permitted use, you will need to obtain permission directly from the copyright holder. To view a copy of this license, visit http://creativecommons. org/licenses/by/4.0/.

\section{References}

1. Woolf CJ. What is this thing called pain? J Clin Invest. 2010;120:3742-4.

2. Baron R, Maier C, Attal N, Binder A, Bouhassira D, Cruccu G, et al. Peripheral neuropathic pain: a mechanism-related organizing principle based on sensory profiles. Pain. 2017;158:261-72.

3. Fond G, Boyer L, Andrianarisoa M, Godin O, Bulzacka E, Berna F, et al. Self-reported pain in patients with schizophrenia. Results from the national first-step FACE-SZ cohort. Prog Neuropsychopharmacol Biol Psychiatry. 2018;85:62-8.

4. Costigan M, Belfer I, Griffin RS, Dai F, Barrett LB, Coppola G, et al. Multiple chronic pain states are associated with a common amino acid-changing allele in KCNS1. Brain: $\mathrm{J}$ Neurol. 2010;133:2519-27.

5. Rodieux F, Piguet V, Berney P, Desmeules J, Besson M. Pharmacogenetics and analgesic effects of antidepressants in chronic pain management. Pers Med. 2015;12:163-75.

6. Le-Niculescu H, Levey DF, Ayalew M, Palmer L, Gavrin LM, Jain N, et al. Discovery and validation of blood biomarkers for suicidality. Mol Psychiatry. 2013;18:1249-64.

7. Niculescu AB, Levey DF, Phalen PL, Le-Niculescu H, Dainton $\mathrm{HD}$, Jain N, et al. Understanding and predicting suicidality using a combined genomic and clinical risk assessment approach. Mol Psychiatry. 2015;20:1266-85.

8. Levey DF, Niculescu EM, Le-Niculescu H, Dainton HL, Phalen PL, Ladd TB, et al. Towards understanding and predicting suicidality in women: biomarkers and clinical risk assessment. Mol Psychiatry. 2016;21:768-85.

9. Niculescu AB, Le-Niculescu H, Levey DF, Phalen PL, Dainton HL, Roseberry K, et al. Precision medicine for suicidality: from 
universality to subtypes and personalization. Mol Psychiatry. 2017;22:1250-73.

10. Niculescu AB, Levey D, Le-Niculescu H, Niculescu E, Kurian SM, Salomon D. Psychiatric blood biomarkers: avoiding jumping to premature negative or positive conclusions. Mol Psychiatry. 2015;20:286-8.

11. Niculescu AB, Le-Niculescu H. Dissecting suicidality using a combined genomic and clinical approach. Neuropsychopharmacol: Off Publ Am Coll Neuropsychopharmacol. 2017; 42:360.

12. Chen R, Mias GI, Li-Pook-Than J, Jiang L, Lam HY, Chen R, et al. Personal omics profiling reveals dynamic molecular and medical phenotypes. Cell. 2012;148:1293-307.

13. Niculescu AB, Le-Niculescu H. Convergent functional genomics: what we have learned and can learn about genes, pathways, and mechanisms. Neuropsychopharmacol: Off Publ Am Coll Neuropsychopharmacol. 2010;35:355-6.

14. Gandal MJ, Haney JR, Parikshak NN, Leppa V, Ramaswami G, Hartl C, et al. Shared molecular neuropathology across major psychiatric disorders parallels polygenic overlap. Science. 2018;359:693-7.

15. Petrosky E, Harpaz R, Fowler KA, Bohm MK, Helmick CG, Yuan K, et al. Chronic pain among suicide decedents, 2003 to 2014: Findings from the national violent death reporting system. Ann Int Med. 2018;169:448-55.

16. Chen R, Mias GI, Li-Pook-Than J, Jiang L, Lam HY, Miriami E, et al. Personal omics profiling reveals dynamic molecular and medical phenotypes. Cell. 2012;148:1293-307.

17. Piening BD, Zhou W, Contrepois K, Rost H, Gu Urban GJ, Mishra T, et al. Integrative personal omics profiles during periods of weight gain and loss. Cell Syst. 2018;6:157-70 e158.

18. Karczewski KJ, Snyder MP. Integrative omics for health and disease. Nat Rev Genet. 2018;19:299-310.

19. Lillie EO, Patay B, Diamant J, Issell B, Topol EJ, Schork NJ. The n-of-1 clinical trial: the ultimate strategy for individualizing medicine? Pers Med. 2011;8:161-73.

20. Schork NJ. Personalized medicine: Time for one-person trials. Nature. 2015;520:609-11.

21. Hur J, Sullivan KA, Pande M, Hong Y, Sima AA, Jagadish HV, et al. The identification of gene expression profiles associated with progression of human diabetic neuropathy. Brain: J Neurol. 2011;134(Pt 11):3222-35.

22. Gruber HE, Hoelscher GL, Ingram JA, Hanley EN Jr. Genome-wide analysis of pain-, nerve- and neurotrophin -related gene expression in the degenerating human annulus. Mol Pain. 2012;8:63.

23. Bell RL, Kimpel MW, McClintick JN, Strother WN, Carr LG, Liang $\mathrm{T}$, et al. Gene expression changes in the nucleus accumbens of alcohol-preferring rats following chronic ethanol consumption. Pharmacol Biochem Behav. 2009;94:131-47.

24. Le-Niculescu H, Balaraman Y, Patel S, Tan J, Sidhu K, Jerome $\mathrm{RE}$, et al. Towards understanding the schizophrenia code: an expanded convergent functional genomics approach. Am J Med Genet B Neuropsychiatr Genet. 2007;144B:129-58.

25. Le-Niculescu H, McFarland MJ, Ogden CA, Balaraman Y, Patel $\mathrm{S}$, Tan J, et al. Phenomic, convergent functional genomic, and biomarker studies in a stress-reactive genetic animal model of bipolar disorder and co-morbid alcoholism. Am J Med Genet B Neuropsychiatr Genet. 2008;147B:134-66.

26. Liu CJ, Dib-Hajj SD, Black JA, Greenwood J, Lian Z, Waxman SG. Direct interaction with contactin targets voltage-gated sodium channel $\mathrm{Na}(\mathrm{v}) 1.9 / \mathrm{NaN}$ to the cell membrane. J Biol Chem. 2001;276:46553-61.

27. Olausson P, Ghafouri B, Backryd E, Gerdle B. Clear differences in cerebrospinal fluid proteome between women with chronic widespread pain and healthy women - a multivariate explorative cross-sectional study. J Pain Res. 2017;10:575-90.

28. Miura Y, Devaux JJ, Fukami Y, Manso C, Belghazi M, Wong $\mathrm{AH}$, et al. Contactin $1 \mathrm{IgG} 4$ associates to chronic inflammatory demyelinating polyneuropathy with sensory ataxia. Brain: a $\mathrm{J}$ Neurol. 2015;138(Pt 6):1484-91.

29. Focking M, Lopez LM, English JA, Dicker P, Wolff A, Brindley E, et al. Proteomic and genomic evidence implicates the postsynaptic density in schizophrenia. Mol Psychiatry. 2015;20:424-32.

30. Vawter MP, Ferran E, Galke B, Cooper K, Bunney WE, Byerley W. Microarray screening of lymphocyte gene expression differences in a multiplex schizophrenia pedigree. Schizophr Res. 2004;67:41-52.

31. Cao-Lei L, Massart R, Suderman MJ, Machnes Z, Elgbeili G, Laplante DP, et al. DNA methylation signatures triggered by prenatal maternal stress exposure to a natural disaster: Project Ice Storm. PLoS ONE. 2014;9:e107653.

32. Hammamieh R, Chakraborty N, Gautam A, Miller SA, Muhie S, Meyerhoff J, et al. Transcriptomic analysis of the effects of a fish oil enriched diet on murine brains. PLoS ONE. 2014;9:e90425.

33. Parisien M, Khoury S, Chabot-Dore AJ, Sotocinal SG, Slade GD, Smith SB, et al. Effect of human genetic variability on gene expression in dorsal root ganglia and association with pain phenotypes. Cell Rep. 2017;19:1940-52.

34. Descalzi G, Mitsi V, Purushothaman I, Gaspari S, Avrampou K, Loh YE, et al. Neuropathic pain promotes adaptive changes in gene expression in brain networks involved in stress and depression. Sci Signal. 2017;10.

35. Smith SB, Maixner DW, Fillingim RB, Slade G, Gracely RH, Ambrose $\mathrm{K}$, et al. Large candidate gene association study reveals genetic risk factors and therapeutic targets for fibromyalgia. Arthritis Rheum. 2012;64:584-93.

36. Hoyo-Becerra C, Huebener A, Trippler M, Lutterbeck M, Liu ZJ, Truebner $\mathrm{K}$, et al. Concomitant interferon alpha stimulation and TLR3 activation induces neuronal expression of depressionrelated genes that are elevated in the brain of suicidal persons. PLoS ONE. 2013;8:e83149.

37. Chang X, Liu Y, Hahn CG, Gur RE, Sleiman PMA, Hakonarson H. RNA-seq analysis of amygdala tissue reveals characteristic expression profiles in schizophrenia. Transl Psychiatry. 2017;7: e1203.

38. Saetre P, Emilsson L, Axelsson E, Kreuger J, Lindholm E, Jazin E. Inflammation-related genes up-regulated in schizophrenia brains. BMC Psychiatry. 2007;7:46.

39. Breen MS, Maihofer AX, Glatt SJ, Tylee DS, Chandler SD, Tsuang MT, et al. Gene networks specific for innate immunity define posttraumatic stress disorder. Mol Psychiatry. 2015;20:1538-45.

40. Le-Niculescu H, Case NJ, Hulvershorn L, Patel SD, Bowker D, Gupta J, et al. Convergent functional genomic studies of omega-3 fatty acids in stress reactivity, bipolar disorder and alcoholism. Transl Psychiatry. 2011;1:e4.

41. Liu J, Lewohl JM, Harris RA, Iyer VR, Dodd PR, Randall PK, et al. Patterns of gene expression in the frontal cortex discriminate alcoholic from nonalcoholic individuals. Neuropsychopharmacology. 2006;31:1574-82.

42. Andrus BM, Blizinsky K, Vedell PT, Dennis K, Shukla PK, Schaffer DJ, et al. Gene expression patterns in the hippocampus and amygdala of endogenous depression and chronic stress models. Mol Psychiatry. 2012;17:49-61.

43. Lamb J, Crawford ED, Peck D, Modell JW, Blat IC, Wrobel MJ, et al. The Connectivity Map: using gene-expression signatures to connect small molecules, genes, and disease. Science. 2006;313: 1929-35.

44. Lamb J. The Connectivity Map: a new tool for biomedical research. Nat Rev Cancer. 2007;7:54-60. 